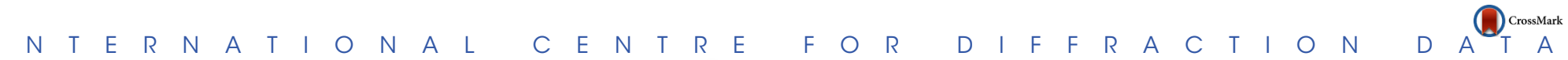

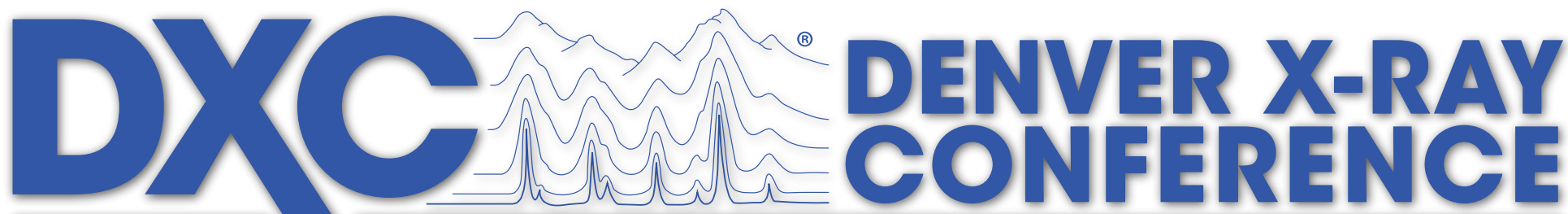

31 July - 4 August 2017 • Big Sky Resort, Big Sky, Montana, USA

\title{
2017 Program
}
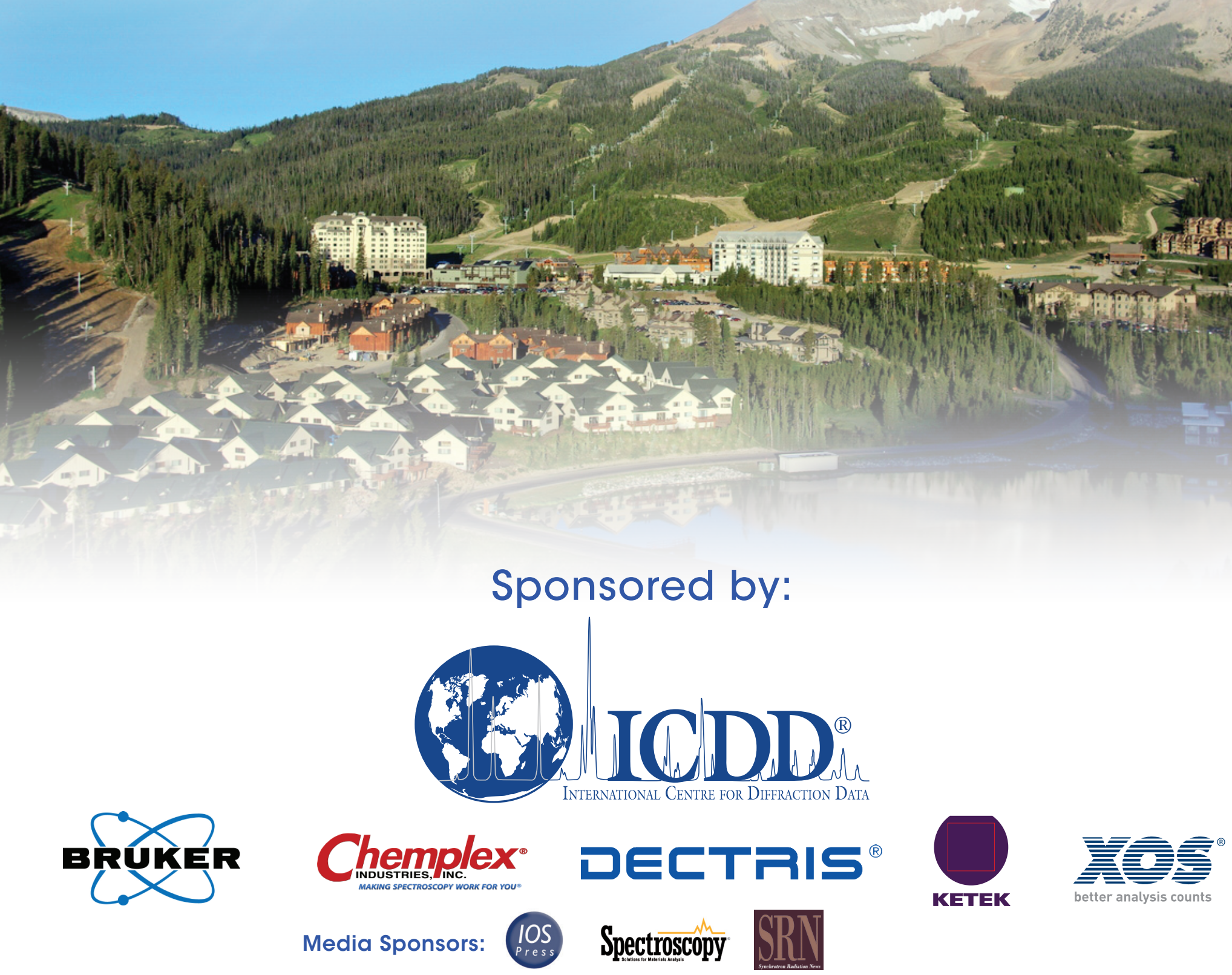

The information contained in this PDF is current as of April 2017. Updates to the Program can be viewed on the Program page of the Denver X-ray Conference website: 


\section{DENVER X-RAY CONFERENCE ORGANIZING COMMITTEE}

Tim Fawcett, Chair, Emeritus ICDD, Newtown Square, PA, DXCfawcett@outlook.com

W. Tim Elam, Past Chair, University of Washington APL, Seattle, WA, wtelam@apl.washington.edu

Tom Blanton, ICDD, Newtown Square, PA, tblanton@icdd.com

John Anzelmo, Anzelmo \& Associates, Inc., Madison, WI, jaanzelmo@aol.com

Lora Brehm, Dow Chemical Company, Midland, MI, Ilbrehm@dow.com

Don Broton, Construction Technology Labs, Skokie, IL, dbroton@ctlgroup.com

James A. Kaduk, Poly Crystallography Inc., Illinois Institute of Technology, \& North Central College, IL, kaduk@polycrystallography.com

Terry Maguire, ICDD, Newtown Square, PA, maguire@icdd.com

Scott Misture, NYS College of Ceramics at Alfred University, Alfred, NY, misture@alfred.edu

Conal Murray, IBM T.J. Watson Research Center, Yorktown Heights, NY, conal@us.ibm.com

Cev Noyan, Columbia University, New York, NY, icn2@columbia.edu

Brian Toby, Argonne National Laboratory, Advanced Photon Source, Argonne, IL, brian.toby@anl.gov

Rene van Grieken, University of Antwerp, Antwerp, Belgium, rene.vangrieken@uantwerpen.be

Mary Ann Zaitz, IBM, Hopewell Junction, NY, zaitz@us.ibm.com

Denise Zulli, ICDD, Newtown Square, PA, zulli@icdd.com

MEMBERS EMERITUS:

Victor Buhrke, Portola Valley, CA

Clay Ruud, Allison Park, PA

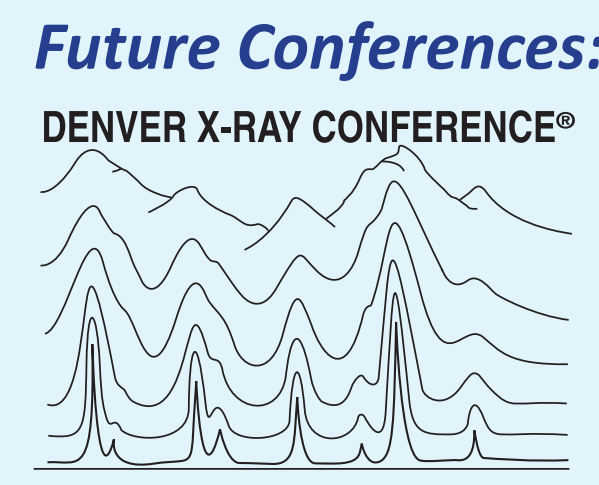

\section{6-10 August 2018 \\ The Westin Westminster, Westminster, Colorado, USA}

5-9 August 2019

The Westin Lombard Yorktown Center, Lombard, IL, USA 


\section{TABLE OF CONTENTS}

Exhibitors. Page 1

\section{Workshops}

Monday Morning Workshops (9:00 am - 12:00 pm) Page 2

- Getting Started at User Facilities

- Specimen Preparation of XRD

- Basic XRF

- Trace Analysis including TXRF

Monday Afternoon Workshops (1:30 pm - 4:30 pm) Page 3

- Stress

- Polymers

- Energy Dispersive XRF

- Micro XRF

\section{Poster Sessions}

Poster Sessions (5:00 pm - 7:00 pm)

- Monday XRD Poster Session Pages 6-8

- Tuesday XRF Poster Session Pages 9-11

\section{Oral Sessions}

Wednesday Morning Session

- Plenary Session: Inspecting the Infrastructure Safeguarding with X-rays

Wednesday Afternoon Sessions.

Pages 12-14

- New Developments in XRD \& XRF Instrumentation I

- Stress and Infrastructure

- Rietveld

- Quantitative Analysis of XRF

Thursday Morning Sessions Pages 15-18

- New Developments in XRD \& XRF Instrumentation II

- Imaging I

- Mineral Exploration and Mining

- Polymers

- General XRF and Environmental XRF

Program-At-A-Glance. Page 24
Tuesday Morning Workshops (9:00 am - 12:00 pm) Page 4

- Rietveld I

- Handheld XRF - The Silver Bullet or Fools Gold

- Challenges in XRF Analysis

- Quantitative Analysis I

Tuesday Afternoon Workshops (1:30 pm - 4:30 pm) Page 5

- Strain \& Phase Mapping of Industrial Materials \& Processing by Synchrotron

- Rietveld II

- Sample Preparation of XRF

- Quantitative Analysis II
Thursday Afternoon Sessions.

Pages 19-21

- Imaging II

- Applied Materials I

- General XRD

- Trace Analysis including TXRF

Friday Morning Sessions Pages 22-23

- Energy Storage Materials

- Applied Materials II

- Pair Distribution Function

- Industrial Applications of XRF 


\section{DENVER X-RAY CONFERENCE EXHIBITORS*}

AMPTEK, Inc.

Angstrom, Inc.

AXO DRESDEN GmbH / Huber

Diffraction Equipment

Brightspec NV/SA

Bruker

Cambridge University Press

Chemplex Industries, Inc.

DECTRIS Ltd.

Excillum $A B$

Heraeus

Herzog Automation Corp.

Hitachi High Tech Science America, Inc.

IFG / Fischer Technology, Inc.

International Centre for Diffraction Data

IXRF Systems, Inc.

KETEK

LGC ARMI

Materials Data, Inc.

Materion Electrofusion

Micro X-Ray, Inc.
Micromatter Technologies, Inc.

Oxford Instruments

PANalytical, Inc.

PNDetector GmbH

PREMIER Lab Supply, Inc.

Proto

Pulstec USA, Inc.

RaySpec Ltd

Rigaku Americas Corporation

Shanghai Shuosong Electronics

Technology Col., Limited

Shimadzu Scientific Instruments, Inc.

Solid Sealing Technology

SPECTRO Analytical Instruments

SPEX SamplePrep/Katanax

STOE + Cie GmbH

SUNJE

Thermo Fisher Scientific

XIA LLC

XOS 


\section{Denver X-ray Conference Workshops \\ Morning Workshops - 9:00 am - 12 Noon \\ Afternoon Workshops - 1:30 pm - 4:30 pm}

\section{Monday Morning Workshops 9:00 am - 12:00 Noon}

Getting Started at User Facilities

North Mammoth

Organizer \& Instructors:

S.H. Lapidus, APS - Argonne National Laboratory, USA, slapidus@aps.anl.gov

A. Huq, Spallation Neutron Source - Oak Ridge National Laboratory, USA, huq@ornl.gov

J. Wright, Illinois Institute of Technology, USA, jwright@csri.iit.edu

K.H. Stone, SLAC - Stanford University, USA, khstone@slac.stanford.edu

This workshop will introduce the capabilities of user facilities, with particular focus on synchrotrons and neutron facilities. Topics covered will include designing experiments, synchrotron PXRD, neutron PXRD, X-ray fluorescence, EXAFS, various other diffraction techniques (such as grazing incidence, thin film, etc.), and how to write a proposal for a user facility. This course does not suppose any knowledge of user facilities, but does suppose a basic knowledge of diffraction and/or fluorescence.

\section{Specimen Preparation of XRD}

Amphitheatre

Organizer \& Instructors:

T. Fawcett, International Centre for Diffraction Data, USA, dxcfawcett@outlook.com

S. Quick, Pennsylvania State University, USA, quick@cse.psu.edu

M. Rodriguez, Sandia National Laboratory, USA, marodri@sandia.gov

Specimen preparation is often the limiting step for obtaining good results in a diffraction experiment. Preparation methods can influence the accuracy and precision of peak positions, intensities and profile. These are the basic measurements required for qualitative and quantitative analysis. The presentation will focus on crystallite and particle effects, orientation and texture, particle statistics and how various preparation methods can reduce or eliminate these influences.

We will also focus on "tricks of the trade" and various techniques that experts use to analyze odd shaped parts, limited samples, as well as, air and moisture sensitive specimens.

\section{Basic XRF}

South Mammoth

Organizer \& Instructors:

A. Drews, Ford Motor Company, USA, adrews@ford.com

K. Kawakyu, Rigaku Corporation, Japan, kawakyu@rigaku.co.jp

This workshop provides a basic introduction to the principles of XRF specifically aimed at those new to the field. In the first half, there will be a general overview of the XRF technique, including a discussion of the basic principles of X-ray interactions with matter. The emphasis in the first half will be on understanding the underlying physical phenomena, how the technique is applied, optimization of the signal, and approaches to quantitative analysis. In the second half of the workshop, examples of real-world applications will be presented to illustrate some of the challenges and opportunities that the analyst may face. This half will describe a variety of specimen formats and demonstrate the flexibility of the XRF technique.

Trace Analysis Including TXRF

Lamar/Gibbon

Organizer \& Instructors:

P.Wobrauschek, C. Streli, TU Wien - Atominstitut, Austria, wobi@ati.ac.at, streli@ati.ac.at

R. Ayala, Fisichem, Inc., USA and Guatemala, rayala@fisichem.com

K. Tsuji, Osaka City University, Japan, tsuji@a-chem.eng.osaka-cu.ac.jp

N. Kawahara, Rigaku Corporation, Japan, kawahara@rigaku.co.jp

Both beginners and experienced X-ray scientists and applicants, physicists and chemists, should gain information by attending the Trace Analysis workshop. Presentations of most modern techniques and instrumentation for trace element analysis using EDXRS will be given. Physical methods to improve minimum detection limits in XRF by background reduction will be discussed; special emphasis will be on Synchrotron radiation as excitation source. Introduction to Total Reflection XRF (TXRF) and actual instrumentation will show achievable advantages and results in terms of detection limits, sensitivities and detectable elemental range down to light elements (eg.Carbon). Confocal $\mu$-XRF will be presented as method for 2D and 3D spatial resolved elemental imaging. Applications from interesting scientific fields such as environment, microelectronics, forensic, and life science will show the successful use of the importance of the various XRF spectrometric techniques. The possibilities of trace analysis using Wavelength Dispersive XRF will also be covered, showing the benefits and limitations of the technique. A comparison of achievable detection limits with the various techniques on some specific samples will be discussed. 


\section{Monday Afternoon Workshops 1:30 pm - 4:30 pm}

Stress

North Mammoth

Organizers \& Instructors:

I.C. Noyan, Columbia University, USA, icn2@columbia.edu

C. Murray, IBM T.J. Watson Research Center, USA, conal@us.ibm.com

This workshop is intended to introduce novice users to the basic techniques used in diffraction-based residual stress determination. Single exposure, $\sin ^{2}(p s i)$, two-tilt and triaxial stress determination techniques will be introduced and instrumental errors associated with the measurement will be discussed. Examples will be provided that use both laboratory and synchrotron-based techniques, including microbeam measurements. At the end of the seminar, the attendees should be able to evaluate the validity of a diffraction-based stress determination experiment.

\section{Polymers}

Organizers \& Instructors:

Amphitheatre

B. Landes, Dow Chemical Company, USA, bglandes@dow.com

S. Murthy, Rutgers University, USA, murthy@biology.rutgers.edu

The workshop will introduce novices to polymer X-ray scattering and to reintroduce practitioners of the technique to the new developments in over the past decade. The workshop will cover both small- and wide-angle scattering, and discuss measurements that can be carried with in-house X-ray sources as well as at synchrotron radiation facilities. The workshop will start with basics of morphology and the crystalline characteristics of semicrystalline polymers, and instrumentation and principle of the measurement. Following topics will be covered with emphasis on topics of interest to the participants.

1. Methods of measuring relative and absolute crystallinity. Issues in the measurements of crystallinity: Background, amorphous halo, the angular range, and preferred orientation. Separation of size and disorder effects.

2. Texture in polymers. Significance of orientation. Determination of orientation in polymers. Amorphous and crystalline orientation.

3. Small-angle X-ray scattering. Void scattering and size analysis. Lamellar and fibrillar structure in polymers.

4. Special techniques: Grazing-incidence measurements. Surface and thin films analysis. Reflectivity. GI-SAXS and GI -WAXS. Microdiffraction.

5. Synchrotron radiation and its use in polymer diffraction in-situ deformation and DSC.

Specific topics that are of broad interest and falling within the scope can be submitted for consideration in advance to the organizers: Sanjeeva Murthy (Murthy@biology.rutgers.edu) and Brian Landes (BGLandes@dow.com).

\section{Energy Dispersive XRF}

South Mammoth

Organizer \& Instructors:

P. Lemberge, Thermo Fisher Scientific, Switzerland, pascal.lemberge@thermofisher.com

W.D. Watson, Thermo Fisher Scientific, USA, wayne.watson@thermofisher.com

This workshop is designed to provide a discussion of the theoretical and practical aspects of EDXRF spectrometry providing a comprehensive review of the basic fundamentals for both the beginner and experienced X-ray spectroscopist. Topics to be covered include excitation systems; detectors; components and their relation to EDXRF applicability; ease of use; rapid qualitative analysis and material screening; calibration techniques for quantitative analysis; standard-less analysis; sensitivity of EDXRF for a wide variety of elements in various matrices as well as sample preparation. We discuss some real-life application examples where EDXRF is being used to solve complex analytical problems. The major emphases will be on the applicability of EDXRF and the optimal protocol for generating and reporting of reliable experimental results.

Micro XRF

Lamar/Gibbon

Organizer \& Instructors:

K.C. Witherspoon, IXRF Systems, Inc., USA, kennyw@ixrfsystems.com

The MXRF workshop will provide an overview of micro X-ray fluorescence (MXRF) including a survey of applications and capabilities as well as an in-depth discussion on common components used in MXRF instruments. The workshop will explore quantitative analysis in addition to elemental imaging (mapping/scanning) as well as their particularities. 


\section{Tuesday Morning Workshops 9:00 am - 12 Noon}

\section{Rietveld Refinement using In Situ Powder Diffraction Data I}

Organizers \& Instructors:

A. Yakovenko, APS - Argonne National Laboratory, USA, ayakovenko@aps.anl.gov

J.A. Kaduk, Polycrystallography, Inc., and Illinois Institute of Technology, USA, kaduk@ polycrystallography.com

K.M. Wiaderek, S. Lapidus, APS - Argonne National Laboratory, USA, kwiaderek@aps.anl.gov, slapidus@aps.anl.gov

Software: GSAS-II

Today, structure determination and structure analysis of new materials is one of the routine tasks which needs to be performed in order to understand the materials properties. The majority of structure determinations are carried out by single crystal methods. Materials that are being used in the industrial and/or commercial settings are, however, generally in polycrystalline form. While new structure solution using powder diffraction data may be complicated, powder diffraction can be easily used for in situ and operando structural studies once structural models are known. This enables a better understanding of the material structure and microstructure, and their evolution at real applicable conditions. In situ powder diffraction methods should become a new popular second step after initial structure determination due to recent advantages in sequential and parametric Rietveld analysis.

The 2017 Rietveld Refinement workshop, in addition to "classical" single pattern data refinement, will be focused on strategies of in situ data processing. We will explore carbon monoxide oxidation process and will see what structural changes happens inside $\mathrm{Cu} / \mathrm{CuxO}$ catalyst. About one quarter of the time will be spent describing how to use other structural techniques such as pair distribution function analysis (PDF) to extract structural information where the Rietveld method might not yield the desired results.

Handheld XRF - The Silver Bullet or Fool's Gold?

North Mammoth Organizer \& Instructors:

M. Loubser, GeoMagGeoChem, South Africa, maggi.loubser@gmail.com

N. Brand, Geochemical Services Pty Ltd, Australia, nwbrand@bigpond.net.au

L. Lee, Getty Conservation Institute, USA, lylee@getty.edu

X-ray Fluorescence spectroscopy is a mature technique with the theory well described and routinely applied in process control, exploration, mining and manufacturing apart from research and development applications. The "big shrink" as in most analytical technologies was the result of improved electronics and computer chips, and together with the advance of the SDD detector Energy Dispersive XRF was ready to enter the playground. Handheld XRF moved from a metal sorting scanner to an actual quantitative analytical tool. But here lies the biggest challenge; because of reduced cost and ease of operation this tool is now more accessible to people who often do not have the insight in the limitations.

In this workshop, firstly the differences between analysis in the field vs. the laboratory would be explained, and methods to improve accuracy or interpret the data based on the know inaccuracies. Then some specific Geology case studies would be presented by Nigel Brand and lastly Lynn Lee will introduce some case studies in the field of art and conservation where the ability to bring a non-destructive technique to the actual object probably had the biggest impact, but again, not without pitfalls.

\section{Challenges in XRF Analysis: Sample Preparation, Spectral Interpretation and Soft X-ray Detection}

South Mammoth

Organizer \& Instructors:

J. Kawai, Kyoto University, Japan, kawai.jun.3x@kyoto-u.ac.jp

Y. Uehara, Mitsubishi Electric Corporation, Japan, uehara.yasushi@aj.mitsubishielectric.co.jp

S. Ichikawa, Fukuoka University, Japan, sichikawa@fukuoka-u.ac.jp

This workshop provides a technical introduction on the following topics:

1. The sample preparation (sample amount, particle size for e.g. rice as received or pulverized based on escape depth of fluorescent X-ray, pressure to make a briquette, glass bead components and thickness, specimen diameter, synthetic standard for calibration curve, validation using reference materials ...)

2. Spectrometer settings (A/D conversion gain, smoothing, background subtraction, dwelling time, iteration time, WDX or EDX, X-ray intensity and counting rate, sum peak, escape peak, diffraction peak, shaping time ...)

3. Measurement conditions (sample thickness, monochromatic X-ray energy, incident X-ray beam angle ...) which will affect the results of quantitative and even qualitative results of XRF. Though synchrotron radiation XRF and EPMA are compared with ordinary laboratory or handheld XRF spectrometers, the workshop is intended to make use of ordinary laboratory XRF spectrometer's high reliability. This workshop is intended not only for XRF beginners but also for those already familiar with XRF measurements.

\section{Quantitative Analysis I}

Lamar/Gibbon

Organizer \& Instructors:

W.T. Elam, University of Washington, USA, wtelam@apl.washington.edu

B. Vrebos, PANalytical B.V., The Netherlands, bruno.vrebos@panalytical.com

K. Kawakyu, Rigaku Corporation, Japan, kawakyu@rigaku.co.jp

Morning:

Matrix effects and how to compensate for them: scatter peaks, compensation methods, semi-quantitative analysis using FP, and fusion.

Afternoon:

Introduction to mathematics and physics of XRF quantification, including matrix effects, spectrum processing, artifacts, instrument settings, and element sensitivity \& detection limits. 


\section{Tuesday Afternoon Workshops 1:30 pm - 4:30 pm}

Strain \& Phase Mapping of Industrial Materials \& Processing by Synchrotron

North Mammoth

Organizer \& Instructors:

T. Tsakalakos, Rutgers University, USA, tsakalak@gmail.com

J. Okasinski, APS - Argonne National Laboratory, USA, okasinski@aps.anl.gov

W.E. Mayo, Polymorph Experts, USA, wemayo@polymorphexperts.com

This workshop will focus on the general principles of strain and phase mapping using synchrotron radiation to interrogate a wide range of advanced engineering materials. X-ray diffraction can be utilized to systematically and comprehensively understand the effects of processing and the resultant evolution of structure on the overall mechanical properties, performance, and thermal stability for materials. Standardized procedures for the testing and analyses of size-dependent mechanical and functional properties at the nanoscale, which are essential for the design, modeling, and life assessment of advanced engineering materials for structural and functional applications, will also be addressed.

Unique experimental techniques, in particular energy dispersive X-ray diffraction (EDXRD), will be reviewed in this workshop for the in situ and ex situ characterization of the structure, residual stresses, and fracture and fatigue response. Systematic and well-executed experiments to investigate monotonic and cyclic deformation and failure across nanometer to macroscopic length scales are discussed in carefully chosen and synthesized model systems. We will discuss techniques to directly measure the residual stress tensor in materials as a function of depth, to correlate the residual stress profiling to deformation and fracture processes of advanced engineering materials and to relate deformation modes to structural parameters.

Rietveld Refinement using In Situ Powder Diffraction Data II Amphitheatre Please see previous description from Rietveld Refinement using In Situ Powder Diffraction Data I, page 4.

Sample Preparation of XRF

South Mammoth

Organizer \& Instructors:

J.A. Anzelmo, Anzelmo \& Associates, Inc., USA, jaanzelmo@aol.com

J. Pitre, Claisse, Canada, jpitre@claisse.com

This workshop will begin with John Anzelmo discussing the fundamental physics of sample preparation, such as infinite thickness and effective layer thickness, particle size effects, mineralogical effects, grinding concepts, and how to make the basic laboratory operations involved in solving these problems for XRF specimen preparation of pressed powders and fusion beads. Janice Pitre will discuss basic and advanced fusion techniques, such as selection of flux for different applications, conditions that cause cracking in beads, and oxidation techniques for simple and difficult to flux materials.

Quantitative Analysis II

Lamar/Gibbon

Please see previous description from Quantitative Analysis I, page 4. 


\section{XRD Poster Session - Monday Evening \\ Huntley Dining Room}

The Monday evening XRD poster session will be held 5:00 pm - 7:00 pm

in the Huntley Dining Room, in conjunction with a wine and cheese reception.

Three "Best Poster" awards will be given at the end of the session, including "Best Student Poster". Judges: T.R. Watkins, Oak Ridge National Laboratory, USA, watkinstr@ornl.gov

M.A. Rodriguez, Sandia National Laboratory, USA, marodri@sandia.gov

*Signifies presenting author, when noted

D-1 The Rietveld of Teaching Materials for Ceramic

J.R. Marques, J.F. dos R. Sobrinho, A.R. do N. Santos. A. de S. Brandim, Instituto Federal do Piauí - IFPI, Brasil

R. Barbosa, Universidade Federal do Piauí - UFPI, Brasil

D-2 Rietveld Analysis of X-ray Powder Diffraction Patterns of Zr-Based Alloy System

C. Silva, K. Leonard, Oak Ridge National Laboratory, USA

F. Ibrahim, Earlham College, USA

D-4 Structure Investigation of Lignin-based Polyurethanes using WAXS

K. Walbrueck, S. Klein, J. Rumpf, M. Schulze, S. Witzleben, Bonn-Rhein-Sieg University, Germany

D-6 Dilithium (Citrate) Crystals and Their Relatives

J.A. Kaduk, A.J. Cigler, North Central College, USA

D-7 Crystal Structures of Large-Volume Commercial Pharmaceuticals

J.A. Kaduk, Illinois Institute of Technology and North Central College, USA

A.M. Gindhart, T.N. Blanton, ICDD, USA

D-8

Determination of Crystallite Size and Strain: A Comparison of Different X-ray Diffraction Techniques

J. Shi, A. Takase, Rigaku Americas, USA

D-9 A High-Quality Non-Destructive XRD Technique for Cultural Heritage

G.M. Hansford*, S.M.R. Turner, University of Leicester, UK

P. Degryse, K.U. Leuven, Belgium

A.J. Shortland, Cranfield University, UK

D-14 Atom Dynamic of Amorphous Materials $\left(\mathrm{Ni}_{0.60} \mathrm{Nb}_{0.4}\right)_{100-\mathrm{x}} \mathrm{Zr}_{\mathrm{x}}(\mathrm{x}=\mathbf{0}$ to 30$)$ by $\mathrm{X}$-ray Photon Correlation Spectroscopy, Neutron Studies

S. Sarker, D. Chandra, Q. An, W.M. Chien, University of Nevada, Reno, USA

B. Ruta, European Synchrotron Radiation Facility, France

T.J. Udovic, NIST Center for Neutron Research, USA

G. King, Los Alamos National Laboratory, USA

D. Isheim, Northwestern University, USA

D-15 Finger Print Minerals for Provenance Estimation of Atamadai Type Pottery (2500-1500 BC) from Hinoki Site (Tochigi, Japan) using Powder XRD

S. Ichikawa*, M. Morikawa, T. Kurisaki, T. Yamaguchi, Fukuoka University, Japan

D-19 Residual Stress Analysis of Coated Carbides at Kennametal, Inc.

T. Shibata*, B. Sargent, Kennametal Inc., USA

D-25 Investigation of Polymer Coating Morphology with XRD

P. Ricou*, A. Du, Z. Cherian, Arkema, Inc., USA

D-26 Time Resolved X-ray Diffraction Study of Ultrasonically Levitated Droplets

Y.I. Kim, K.B. Kim, Y.H. Lee, Korea Research Institute of Standards and Science, Republic of Korea

K.M. Nam, Mokpo National University, Republic of Korea

D-30 Synchrotron Powder Diffraction Simplified: The High-Resolution Diffractometer 11-BM at the Advanced Photon Source

L. Ribaud, S. Lapidus, Argonne National Laboratory, USA 
D-31 Materials Characterization Using Synchrotron Radiation Capabilities of the ICDD PDF-4 Databases T. Blanton, T. Fawcett, J. Blanton, S. Kabekkodu, R. Papoular, ICDD, USA

D-32 Phase Transformation and Enhancement of Structural Properties on CdSe Films with Annealing in Air Atmosphere

J. Sarmiento, E. Rosendo, T. Díaz-Becerril, R. Romano-Trujillo, CIDS, BUAP, México

W. De la Cruz, CNYN, UNAM, México

D-33 Materials Characterization Using Neutron Radiation Capabilities of the ICDD PDF-4 Databases

T. Blanton*, J. Faber, J. Blanton, S. Kabekkodu, R. Papoular, ICDD, USA

D-35 Determination of Contrast Factors for Cubic Slip-Systems and their Application in the Microstructural Characterization of Binary Fm-3m Materials

D. Cavazos-Cavazos, F.F. Contreras-Torres, Tecnológico de Monterrey, Mexico

D-36 Hydrotalcites as a Carbon Sink in Serpentinites

C.C. Turvey*, S.A. Wilson, J.L. Hamilton, Monash University, Australia

J. McCutcheon, G. Southam, The University of Queensland, Australia

A. Beinlich, Curtin University, Australia

G.M. Dipple, The University of British Columbia, Canada

D-38 Determination of Clay Minerals by the Rietveld Refinement

M. Kasari*, D. Fukuda, K. Fujii, Y. Koike, Meiji University, Japan

A. Ohbuchi, Rigaku Corporation, Japan

D-39 Powder XRD Investigations and Structure Solution of ULS-1 - a New Layered Silicate Material M.A. Miller, S.R. Miller, R.W. Broach, M.M. Galey, S. Prabhakar, B. Lyons, C.L. Nicholas*, C.P. Nicholas, Honeywell UOP, USA

D-50 Feasibility Study of Manufacturing TiAl Parts with Electron Beam Melting: A Pathway Towards Additively Manufacturing Complex Engine Components

E. Cakmak, P. Nandwana, T. Watkins, A. Haynes, Oak Ridge National Lab, USA

R. England, Cummins Inc., USA

D-51 Synthesis of Li-Sn-Zn Ternary Alloy

C. Saw, B. Choi, Lawrence Livermore Nat. Lab., USA

D-52 A New 3D Framework Supported in Dipolar and Cuadrupolar Interactions: Intercalation of Thiazole in Layered Solids

F. Echevarría, A.A. Lemus-Santana, M. González, E. Reguera, Research Institute in Advanced Science and Applied Technology, México

J. Rodríguez, Research Center in Advanced Chemistry, México

D-56

Porphyrins: Important Materials with Diverse Functionalities

L. Cook, G. Brewer,The Catholic University of America, USA

W. Wong-Ng, National Institute of Standards and Technology, USA

D-96 P-type Behavior of Antimony Doped ZnO Nanowires Studied By X-ray Absorption Spectroscopy and Photoluminescence

A.M. Alsmadi, B. Salameh, Kuwait University, Kuwait

D-61 Disordered and Non-crystalline Phase Quantification with Whole-pattern Fitting in Environmental Materials T.J. Kane*, University of Colorado and U.S. Geological Survey, USA

K.M. Campbell, U.S. Geological Survey, USA

In Operando / Situ Data Collection and Advanced Data Analysis of a Commercial Li-lon Battery During Charge/Discharge Cycles on a XRPD Laboratory Diffractometer

T. Degen, M. Gateshki, M. Sadki, D. Beckers, PANalytical B.V., The Netherlands

STOE STADI P and the MULTI-MYTHEN - The Solution if One Dectris MYTHEN $1 \mathrm{~K}$ is Not Fast Enough

T. Hartmann, Stoe \& Cie GmbH, Germany

Atomic Pair Distribution Function (PDF) and X-ray Scattering Methods to Assess the Stability of Amorphous Organic Compounds

D. Beckers, M. Gateshki, PANalytical B.V., The Netherlands

A. Adibhatla, PANalytical Inc., USA 
D-70 Crystallite Size Analysis of Nanomaterials by Single Peak and Whole Pattern Fitting J. Cowen, Case Western Reserve University, USA

D-71 The High-Temperature Stability and Crystal Structure of Cadmium-Doped Hydroxyapatite Powders M. Shah, G. Gonzalez, DePaul University, USA

D-72 Relationships between Optical and DRX Characteristics of $\mathrm{Cu}^{+2} / \mathrm{Fe}^{+3} \mathrm{Mixed}$ Oxides S. Nieto-Zambrano, E. Ramos-Ramirez, University of Guanajuato, Mexico

D-73 How Low Can You Go? Exploring Lowest Detection Limits of Respirable Crystalline Silica N. Rodesney*, N. Henderson, J. Giencke, B. Jones, Bruker AXS, USA

D-77 D2 PHASER Benchtop Diffractometer: New Components Boost Performance

N. Henderson*, S.N. Rodesney, J. Giencke, B. Jones, Bruker AXS, USA

A. Kern, Bruker AXS, Germany

D-81 Structural Characterization of GaN Layers Grown on Graded-AIGaN/GaN/c-Al ${ }_{2} \mathrm{O}_{3}$ Templates by HRXRD, GIXD, AFM and TEM

A. Kuchuk, H. Stanchu, Yu. Mazur, P. Lytvyn, C. Li, Y. Maidaniuk, M. Benamara, M. Ware, G. Salamo, University of Arkansas, USA

M. Schmidbauer, Leibniz-Institut für Kristallzüchtung, Germany

D-85 Shear Stress Measurement with Portable X-ray Device

S.Y. Lee, Columbia University, USA

D-88 Diffuse Scattering from Nanoparticles

S. Xiong, I.C. Noyan, Columbia University, USA

D-90 Method Development for X-ray Diffraction Analysis of Thin Powder Deposit Samples of Simulated Radioactive Tank Waste

T. Ely, H. Meznarich, T. Valero, G. Cooke, Washington River Protection Solutions LLC, USA

D-91 Alloying Large Organic Cations into the Perovskite Framework for Enhanced Thermal Stability and Transport Properties

W. Peng, X. Miao*, O.M. Bakr, King Abdullah University of Science and Technology (KAUST), Saudi Arabia

D-95 MetalJet Technology and Applications in XRD and SCD

E. Espes*, J. Hållstedt, U. Lundström, B.A.M. Hansson, O. Hemberg, M. Otendal, T. Tuohimaa, P. Takman, Excillum AB, Kista, Sweden

Metal \& Alloy Structure Types in the PDF4+

C.R. Hubbard*, Applied Diffraction Services, USA

P. Wallace, ICDD Editor, USA

Note: Post-deadline posters (abstracts submitted after March 2017) will be listed on the program page of the DXC website: www.dxcicdd.com 


\section{XRF Poster Session - Tuesday Evening \\ Huntley Dining Room}

The Tuesday evening XRF poster session will be held 5:00 pm - 7:00 pm

in the Huntley Dining Room, in conjunction with a wine and cheese reception.

Three "Best Poster" awards will be given at the end of the session, including "Best Student Poster". Judges: To be announced.

*Signifies presenting author, when noted

F-2 XRF Elemental Analysis from Raw Materials to Coated Carbides - Case of Kennametal. Inc

P. Kalvala, A. Comar, B. Sargent, T. Shibata*, Kennametal Inc., USA

F-3 Rapid Quantitative Analysis of Silicon, Calcium, Chromium, Manganese and Iron in Ferrosilicon by Benchtop EDXRF

D.W. Cheng*, M.B. Liu, X.L. Liao, Z.Y. Ni, X.J. Shen, Y.H. Jia, NCS Testing Technology Co., Ltd., China

F-4 Depth Resolved Chemical Speciation of a Superlatice

G. Das, M.K. Tiwari, Raja Ramanna Centre for Advanced Technology, and Homi Bhabha National Institute, India

A. Khooha, A.K. Singh, Raja Ramanna Centre for Advanced Technology, India

Recent Modifications to the Software of a Miniature X-ray Fluorescence Spectrometer for Radiological Glovebox Applications

D.M. Missimer*, P.E. O’Rourke, C.E. Brown, Savannah River National Laboratory, USA

Elemental Mapping of Strontium in Rat Bones Treated with Strontium Ranelate and Strontium Citrate using 3D Dual Energy X-ray K-edge Subtraction Imaging

D.A. Cardenas, A. Pejovic-Milic*, Ryerson University, Canada

D. Cooper, A. Panahifar, University of Saskatchewan, Canada

G. Wohl, McMaster University, Canada

F-16 Versatile Filtering of Charge Sharing in Commercial sCMOS Camera for X-ray Fluorescence Analysis

W. Zhao, University of Tsukuba, Japan

K. Sakurai, National Institute for Materials Science, Japan

F-18 X-ray Analysis of Fouling from CFBC

Y. Kim*, Korea Advanced Institute of Science and Technology, Republic of Korea

K. Park, J. Park, G. Lee, D. Lee, H. Kim, D. Bae, K. Han, D. Shun, Korea Institute of Energy Research, Republic of Korea

F-20 A New Scale in the Technology of Polycapillary Optics

A. Bjeoumikhov; S. Bjeoumikhova; M. Thiel, IFG / Fischer Technology, Inc., Germany

Characterization of Food Contaminants through Micro-XRF

R. Novetsky, Bruker AXS, Inc., USA

Investigating the Effects of Micro-XRF Analysis on Common Geochemical Compounds

S. Menachekanian, California State Polytechnic University, USA

D. Flannery, R. Hodyss, A. Allwood, K. Williford, Jet Propulsion Laboratory, USA

C. Heirwegh, Caltech/Jet Propulsion Laboratory, USA

C.S. Jamieson, Glendale Community College, USA

Characterization of Sub-Log Scale Variability in Mudstones and the Effects of Variable Sampling Scales on High Resolution Models; Examples from Bone Spring Formation, West Texas

A. Morrell*, S. Narasimhan, H. Rowe, P. Mainali, Premier Oilfield Laboratories, USA

X-ray Fluorescence Analysis in an Electron Microscope: Improved Spotsize of Polycapillary Focusing Optics at the IfG Modular X-ray Source (iMOXS $/ 2^{\circledR}$ )

M. Menzel, A. Bjeoumikhov, IfG - Institute for Scientific Instruments GmbH, Germany 
A. Vikharev, Institute of Applied Physics, Russia

S. Stoupin, Chess, Cornell University, USA

PWM Implementation of a Grid Controlled Microfocus X-ray Tube

C. McKenzie, A. Degtraryov, Y. Alivov, M. Chidambaram, B. Grigsby, Oxford Instruments, USA

F-38 MOXTEK MXDPP-60: OEM DPP Performance Characterization

A. Stratilatov, R. Creighton, J. Van Wagoner, C. Carter, J. Wong, S. Kamtekar, Moxtek, Inc., USA

F-44 Silicon Drift Detectors for High Speed X-ray Applications

M. Zhang, S. Barkan, V.D. Saveliev, L. Feng, Y. Wang, B. Goolsby, E.V. Damron, Hitachi High-Technologies

Science America, Inc., USA

Calculation of Fluorescent X-ray Intensity for Confocal micro-XRF Analysis of Inhomogenious Samples - Part 2 N. Kawahara*, R. Hosomi, S. Mita, K. Tsuji, Osaka City University, Japan

F-50 $\quad 120$ kV \& 5 Watt Compact X-ray Source

S. Cornaby, G. Smith, R. Steck, B. Harris, K. Kozaczek, E. Miller, S. Kamtekar, Moxtek Inc., USA

On-line Determination of Rare Earth Distribution by Energy Dispersive X-ray Fluorescence Spectrometry L. Hongwei, Beijing, China

X-ray Fluorescence Computed Tomography at SSRF

B. Deng, B. Feng, G. Du, H. Xie, T. Xiao, SSRF, China

Differentiation and Quantification of Sulfur Species by X-ray Fluorescence (WDX)

S. Uhlig, A. Plessow, TU Bergakademie Freiberg, Germany

R. Möckel, Helmholtz-Institute Freiberg for Resource Technology, Germany

Novel Clustering Approach for the Segmentation of Elemental Distributions in Human Bone

M. Rauwolf*, A. Turyanskaya, P. Wobrauschek, C. Streli, Atominstitut - TU Wien, Austria

A. Roschger, Max Planck Institute of Colloids and Interfaces, Germany

P. Roschger, Hanusch Hospital, Austria

J.G. Hofstaetter, Orthopaedic Hospital Vienna-Speising, Austria

Application of SR-TXRF-XANES for the Analysis of Indoor Aerosol Samples at BESSYII and ELETTRA

J. Prost, A. Zinkl, D. Ingerle, P. Wobrauschek, C. Streli, Atominstitut - TU Wien, Austria

D.M. Eichert, W.H. Jark, ELETTRA - Sincrotrone Trieste, Italy

G. Pepponi, Fondazione Bruno Kessler, Italy

A. Migliori, A.G. Karydas, M. Czyzycki, International Atomic Energy Agency, Austria

A. Guilherme Buzanich, U. Reinholz, H. Riesemeier, M. Radtke, Federal Institute for Materials Research and Testing, Germany

Total-reflection X-ray Fluorescence Analysis of Airborne Particulate Matter Samples

A. Zinkl, J. Prost, J.H. Sterba, P. Wobrauschek, C. Streli, Atominstitut - TU Wien, Austria

Comparison of Synchrotron-Induced X-ray Fluorescence with ED-XRF on the Elemental Analysis of Air Pollution Samples

N. Spada, S. Yatkin, K. Trzepla, N. Hyslop, University of California, Davis, USA

M. Czyzycki, IAEA, Austria and AGH University of Science and Technology, Poland

F-66 Determination of Airborne Mercury using Ag-nano Particles Assisted TXRF

S. Böttger, D. Rosenberg, M. Busker, W. Jansen, Europa-Universität Flensburg, Germany

I.M.B. Tyssebotn, U.E.A. Fittschen*, Washington State University, USA 

Line at Elettra
A. Turyanskaya, L. Perneczky, M. Rauwolf, P. Wobrauschek, C. Streli, Atominstitut - TU Wien, Austria
D. Eichert, F. Brigidi, W. Jark, Elettra Sincrotrone Trieste, Italy
S. Bjeoumikhova, IFG, Institute for Scientific Instruments GmbH, Germany
G. Pepponi, Fondazione Bruno Kessler, Italy
P. Roschger, Hanusch Hospital, Austria

Investigation of the Local Manganese Distribution in Bone in Female and Male Osteoporosis Compared to Healthy Controls

A. Turyanskaya*, M. Rauwolf, T. Bretschneider, P. Wobrauschek, C. Streli, Atominstitut, TU Wien, Austria

A. Roschger, J. Hofstaetter, P. Roschger, Hanusch Hospital, Austria

J. Hofstaetter, Orthopaedic Hospital Vienna-Speising, Austria

I. Zizak, Helmholtz-Zentrum Berlin für Materialien und Energie, Germany

XRF Result Repeatability Across Multiple Uncalibrated Instrument Components

J. Van Wagoner, S. Cornaby, S. Kamtekar, K. Kozaczek, Moxtek, USA

Visualizing Artist's Techniques through Macro-XRF Scanning of Painted Works

D. MacLennan*, C. Schmidt Patterson, L. Lee, N. Daly, K. Trentelman, Getty Conservation Institute, USA Y. Szafran, N. Turner, J. Paul Getty Museum, USA

F-77 In-vivo Micro-XRF to Study Rubidium Uptake in Plants

U.E.A. Fittschen, A. Fittschen*, R. Hoehner, H.-H. Kunz, Washington State University, USA

On-line Analysis of Potassium Chloride on a Conveyor Belt using XRF Combined with Distance Correction Method

X. Zhang, Y. Zhang, Z. Kong, Q. Shan, W. Jia, Nanjing University of Aeronautics and Astronautics, China

F-82 Total Reflection X-ray Fluorescence Analysis of Oysters

L. Borgese*, R. Dalipi, L.E. Depero, University of Brescia, Italy

F-83

Optimized High Energy Performance of Polycapillary Optics for $\mu$ XRF Analysis

J. Sachs, N. Gao, XOS, USA

R. Magyar, Bowman XRF, USA

F-84 Use of Multivariate Analysis for Detecting Orientation Changes in Steel Via Laue Diffraction Artifacts within XRF Spectra

M.A. Rodriguez*, M.H. Van Benthem, J.J.M. Griego, D.F. Susan, P. Yang, C.D. Mowry, D. Enos, Sandia National Laboratories, USA

F-85 Chemical and Structural Analysis of Slags from Steel making Industries

A. Riboldi, M. Brisotto, L. Borgese*, G. Cornacchia, L.E. Depero, University of Brescia, Italy

E. Bemporad, University of Roma Tre, Italy

F-86 Measure Low Concentrations of As, Se and Pb in Water by MWDXRF

X. Zhang, T. Tongue, Z. Chen, X-ray Optical Systems, USA

F-87

New Reference Samples for X-ray Spectrometry

R. Dietsch*, T. Holz, M. Krämer, D. Rogler, D. Weissbach, AXO DRESDEN GmbH, Germany

B. Beckhoff, P. Hoenicke, PTB, Germany

T. Krugmann, University of Hamburg, Germany

D. Rosenberg, University of Flensburg, Germany

S-59 Alpha Particle X-ray Spectrometer onboard Chandrayaan-2 Rover

A. Patel, Physical Research Laboratory, India

Note: Post-deadline posters (abstracts submitted after March 2017) will be listed on the program page of the DXC 


\section{Plenary Session - Wednesday Morning, 2 August \\ 8:30 am - 11:45 am \\ Talus Room}

Inspecting the Infrastructure - Safeguarding with X-rays

Chairs: C. Murray, IBM T.J. Watson Research Center, USA, conal@us.ibm.com

D. Broton, Construction Technology Labs, USA, dbroton@ctlgroup.com

$8: 30$

Welcoming Remarks \& Awards:

Introduction of the new Chairman of the Denver X-ray Conference, Tim Fawcett, Emeritus ICDD, USA, by Past Chairman, W. Tim Elam, University of Washington, USA

2017 Jenkins Award presented to James Kaduk, Polycrystallography, Inc and Illinois Institute of Technology, USA. Presented by Tim Fawcett, Chairman of the Jenkins Award Selection Committee, Emeritus, ICDD, USA

2017 Barrett Award presented to Daniel Louër, France. Presented by Conal Murray, Chairman of the Barrett Award Selection Committee, IBM, USA. Dr. Louër will be unable to attend DXC and will accept the award at the ICDD Annual Meetings in 2018.

2017 Jerome B. Cohen Student Award winner to be announced by Chairman of the Cohen Award Selection Committee, I. Cev Noyan, Columbia University, USA

2017 Robert L. Snyder Student Awards to be announced by Tom Blanton, Executive Director, ICDD, USA

Plenary Session remarks by the Chairs, Conal Murray and Don Broton

Invited Talks

9:00 P-3 Hydraulic Cements for Construction: Cementitious Materials, Standards, Specifications, and X-ray Analysis P. Stutzman, National Institute of Standards and Technology, Gaithersburg, MD, USA

9:45 P-2 The Role of Chemistry in Materials Verification and Troubleshooting G. Seegebrecht, Concrete Consulting Engineers, LLC, West Chester, IL, USA

$10: 30$ Break

11:00 P-1 Neutron Diffraction and the Art of Infrastructure Maintenance I.C. Noyan, Columbia University, New York, NY, USA

\section{Oral Sessions, Wednesday Afternoon, 2 August}

\section{New Developments in XRD/XRF Instrumentation I}

Chairs: T.N. Blanton, International Centre for Diffraction Data, USA, tblanton@icdd.com

T. Fawcett, Emeritus, International Centre for Diffraction Data, USA, dxcfawcett@outlook.com

1:30-1:42 S-4 Geometry and Algorithms to Expand 2theta Coverage of 2D Detector

B. He, Bruker AXS, USA

1:43-1:55 S-15 Simultaneous X-ray Fluorescence and Diffraction Imaging with the Color X-ray Camera

J. Davis*, J. Schmidt, M. Huth, H. Soltau, PNDetector, Germany

R. Hartman, L. Strüder, PNSensor, Germany

1:56-2:08 S-16 STOE STADI P and the MULTI-MYTHEN - Fastest Data Collection, Not Only for In-Situ Experiments

T. Hartmann, Stoe \& Cie GmbH, Germany

2:09-2:21 S-43 Latest Development of Multilayer Optics for Analyzers and Probe Beam Solutions at Rigaku Innovative Technologies

N. Grupido, B. Verman, Y. Platonov, L. Jiang, Rigaku Innovative Technologies, Inc., USA

2:22-2:34 S-56 Pixirad: Unique Hybrid Pixel Technology for X-ray Diffraction, Scattering and Imaging M. Fransen*, A. Noordermeer, E. Reuvekamp, R. de Vries, J. Bolze, F. Masiello, PANalytical B.V., The Netherlands

A. Brez, M. Minuti, M. Pinchera, G. Spandre, Pixirad srl and Istituto Nazionale di Fisica Nucleare, Italy

R. Bellazzini, PANalytical, Pixirad and INFN, Italy 
2:35-2:47 S-8 Improved Performance of Silicon Drift Detectors

A. Pahlke*, R. Fojt, M. Fraczek, L. Höllt, J. Knobloch, N. Miyakawa, J. Rumpff, O. Scheid, A. Simsek, KETEK $\mathrm{GmbH}$, Germany

2:48-3:00 S-9 New Developments in ED-XRF Technology Enable Highly Precise Elemental Analyses

D. Sachter, D. Wissmann, SPECTRO Analytical Instruments $\mathrm{GmbH}$, Germany

M. Daniel-Prowse*, SPECTRO Analytical Instruments Inc., USA

3:00

Break

$\begin{array}{ll}\text { 3:30-3:42 S-18 } & \text { More Features, Improved Integration, HighScore(Plus) V4.6 and Beyond } \\ & \end{array}$

3:43-3:55 S-48 Fast X-ray Sorting for Recycling Light Metals: A Low Cost High Throughput In-Line X-ray Fluorescence Scrap Metal Sorter

M. Garcia, N. Kumar, nanoRANCH-UHV Technologies, Inc., USA

3:56-4:08 S-53 New Innovations in the D2 PHASER Benchtop Diffractometer

B. Jones*, N. Henderson, S. Rodesney, J. Giencke, Bruker AXS, USA

A. Kern, Bruker AXS, Germany

4:09-4:21 S-23 Aeris- PANalytical's New Benchtop XRD with Best in Class Performance

J. Quinn, PANalytical Inc., USA

H. van Weeren, M. Fransen, PANalytical BV, The Netherlands

4:22-4:34 S-52 D8 ADVANCE Plus: The Newest Member of the D8 Family of Solutions

J. Giencke, B. Jones, N. Henderson, N. Rodesney, Bruker, USA

4:35-4:47 S-57 Improving Handheld XRF Performance in Geological Samples

M. Cameron, Bruker Elemental, USA

4:48-5:00 S-38 Newly Developed Compact X-ray Sources

S. Cornaby, T. Parker, R. Steck, B. Harris, K. Kozaczek, C. Smith, E. Miller, S. Kamtekar, Moxtek Inc., USA

Stress and Infrastructure

Amphitheatre

Chair: T.R. Watkins, Oak Ridge National Laboratory, USA, watkinstr@ornl.gov

1:30 D-92

Invited: Complementary Residual Stress Measurement Techniques

M.L. Steinzig*, M.B. Prime, T.A. Sisneros, B. Clausen, C.F. Chen, J. Dereskiewicz, Los Alamos National Laboratory, USA

2:00 D-49 Spatially Resolved Texture and Microstructure Evolution of Gas Gun Deformed SUS304 Steel Using Neutron Diffraction

S. Takajo*, C.P. Trujillo, D.T. Martinez, B. Clausen, D.W. Brown, S.C. Vogel, Los Alamos National Laboratory, USA

2:20 D-86 Temperature Measurement with Neutron Diffraction

S.Y. Lee, I.C. Noyan, Columbia University, USA

2:40 D-21 Asymmetrical Reciprocal Space Mapping using X-ray Diffraction: A Technique for Structural Characterization of III-nitride Nanostructures

A. Kuchuk, University of Arkansas, USA

3:00 Break

3:30 D-87 Strain Determination in Nanoparticles

S. Xiong, I.C. Noyan, Columbia University, USA

3:50 D-68 High-Energy Synchrotron Radiation X-ray Diffraction Measurements for Phase and Residual Strain Mapping of Friction-Stir Processed Beta Titanium Alloys

M. Carl, M.L. Young, University of North Texas, USA

4:10 D-20 Validation of the Material Removal Correction for Residual Stress Measurement Results Obtained Using

X-ray Diffraction Techniques

J. Pineault*, M. Bolla, M. Belassel, Proto Manufacturing Ltd., Canada

M. Brauss, Proto Manufacturing Inc., USA

4:30 D-17 Residual Stress Measurement of Polyethylene Pipes with Two-Dimensional X-ray Diffraction

M. Ren, C. Zheng, Y. Shi, L. Liu, Sinopec Beijing Research Institute of Chemical Industry, China

B.B. He, Bruker AXS, Inc., USA 
Chair: A. Huq, Oak Ridge National Laboratory, USA, huqa@ornl.gov

2:00 D-13 Invited: The Impact of the Rietveld Method in Mineralogy and Geology: The Impossible is now Possible D. Bish, Indiana University, USA

2:30 D-57 Routine Definition of K-feldspar Ordering Degree in Multiphase Rietveld Refinements

R. Möckel, S. Richter, J. Gutzmer, Helmholtz-Institute Freiberg for Resource Technology, Germany

U. Kempe, TU Bergakademie Freiberg, Germany

2:50 D-18 Invited: Powder Diffraction in the Petroleum and Petrochemical Industries

J.A. Kaduk, Illinois Institute of Technology and North Central College, USA

3:20 Break

3:50 D-93 Invited: The Impact of Rietveld in Condensed Matter Science

C.R. Dela Cruz, Oak Ridge National Laboratory, USA

4:20 D-42 Synthesis and Structural Characterization of Small-pore ABC-6 Family Zeotypes

J.P.S. Mowat, G.J. Lewis, R.W. Broach, N. Greenlay, P. Jakubczak, L.M. Knight, S.R. Miller, J. Stanczyk, Honeywell UOP, USA

4:40 D-58 Understanding Reduction Alloying of Core-shell Nanoparticles Through In-situ Powder X-ray Diffraction

R. Koch, S. Misture, Alfred University, USA

G. Li, H. Wang, University of South Carolina, USA

Quantitative Analysis of XRF

South Mammoth

Chair: L. Brehm, Dow Chemical Company, USA, Ilbrehm@dow.com

1:30 F-81 Invited: The Micro Ionome of Plants: An Approach to Quantify lon Uptake and Distribution In Vivo U.E.A. Fittschen, A. Fittschen, R. Hoehner, W. Tramel, H.H. Kunz, Washington State University, USA

2:00 F-22 Reduction of Pile-up Spectra at High Input Count Rates - Mandatory for Trace Element Analysis J. Heckel, SPECTRO Analytical Instruments $\mathrm{GmbH}$, Germany

2:20 F-33 Calibration of a $\mu$-XRF Prototype Instrument used in Modelling the Performance of the Planetary Instrument for X-ray Lithochemistry (PIXL) for Mars 2020

C. Heirwegh, D. Flannery, A. Allwood, Jet Propulsion Laboratory, California Institute of Technology, USA

W.T. Elam, University of Washington, USA

2:40 F-80 Abridged Spectral Matrix Inversion - Fitting 25,000 Spectra Per Second

A.M. Crawford*, O. Ponomarenko, C. Simoens, G. George, I. Pickering, University of Saskatchewan, Canada

3:00 F-31 Where Compton Matters

T. Wolff*, F. Reinhardt, Bruker Nano GmbH, Germany

F. Nitsche, Bruker AXS GmbH, Germany

D. Docenko, Consultant, Israel

3:20 Break

3:50 Invited: Some Aspects of Fundamental Parameters Applied to XRF

B. Vrebos, Panalytical B.V., The Netherlands

4:20 F-56 Invited: Superconducting Microcalorimeters for X-ray Spectroscopy

J. Fowler, NIST Boulder Labs, USA

4:50 F-64 Research of Method for Improving the Accuracy of Online X-ray Fluorescence Analysis in Coal

Y. Zhang, W.B. Jia, Q. Shan, X.L. Zhang, Nanjing University of Aeronautics and Astronautics, China

R. Gardner, North Carolina State University, USA

5:10 $\quad$ K-47 Analysis by FP Calibration Using Standards with Unknown Components

K. Kawakyu*, T. Moriyama, Y. Kataoka, Rigaku Corporation, Japan 


\section{Oral Sessions, Thursday Morning, 3 August}

*Signifies presenting author, when noted

New Developments in XRD/XRF Instrumentation I

North Mammoth

Chairs: T.N. Blanton, International Centre for Diffraction Data, USA, tblanton@icdd.com

T. Fawcett, Emeritus, International Centre for Diffraction Data, USA, dxcfawcett@outlook.com

8:30-8:42 S-7 High-throughput X-ray Powder Diffraction System Consisting of Multiple MYTHEN Detectors at Beamline BL02B2 of SPring-8

K. Sugimoto*, S. Kawaguchi, M. Takemoto, Japan Synchrotron Radiation Research Institute, Japan

8:43-8:55 S-22 Computed Tomography Experiments on a Laboratory Multipurpose Diffractometer

D. Beckers*, N. Dadivanyan, D.J. Götz, M. Fransen, PANalytical, The Netherlands

8:56-9:08 S-51 Non-Invasive Identification of Pigments from XVI Century using an XRD/XRF System

V. Aguilar, J.L. Ruvalcaba, Universidad Nacional Autonoma de Mexico, Mexico

9:09-9:21 S-45 Renewed and Upgraded NIST SRMS for Powder Diffraction

J.P. Cline, D.R. Black, M.H. Mendenhall, A. Henins, NIST, USA

P.S. Whitfield, ORNL, USA

9:22-9:34 S-2 Current Status of the Liquid-Metal-Jet X-ray Source Technology

E. Espes, J. Hållstedt, B. Hansson, U. Lundström, P. Takman, O. Hemberg, M. Otendal, T. Tuohimaa, Excillum AB, Sweden

9:35-9:47 S-47 New User-Customized Calibrations for Handheld pXRF Analysers

C. Brand, Portable Analysers Australia, Australia

M. Cameron, Bruker Elemental, USA

9:48-10:00 S-34 Ultra High Speed Multi-element SDD X-ray Spectrometer with Improved Energy Response

Y. Wang, S. Barkan, L. Feng, V. Saveliev, M. Zhang, Hitachi High-Technologies Science America, Inc., USA

10:00

Break

10:30-10:42 S-28 Advances in a Laboratory X-ray Analytical Microscope with micro X-ray Fluorescence Capabilities toward Significant Gains in Resolution and Sensitivity

W. Yun, B. Stripe*, S. Lewis, D. Reynolds, A. Lyon, J. Kirz, Sigray, USA

10:43-10:55 S-31 The Soft X-ray Microgap (MICROMEGAS) Gas Detector for WDXRF Spectrometers. Prototype Design and First Characterization Data

A. Stratilatov, R. Creighton, J. Barron, Moxtek, Inc., USA

10:56-11:08 S-32 Study of Carbon Bonding with XES using a TES Microcalorimeter Detector

K. McIntosh*, G. Havrilla, M. Croce, R. Huber, D. Podlesak, M. Rabin, Los Alamos National Laboratory, USA

F. Vila, University of Washington, USA

M. Carpenter, R. Cantor, Star Cryoelectronics, USA

11:09-11:21 S-6 XRF Detector System with Hermetically Closed Silicon Drift Detector Modules for High Resolution Spectroscopy in Ambient Air Conditions

H. Schmidt, H. Soltau, A. Niculae, A. Liebel, R. Lackner, D. Steigenhöfer, B. Talbi, M. Bornschlegl, T. Barros, PNDetector GmbH, Germany

11:22-11:34 S-55 Phase Modification Descriptor in the Powder Diffraction File ${ }^{\mathrm{TM}}$

S. Kabekkodu*, International Centre for Diffraction Data (ICDD), USA

C. Crowder, Scientist-Emeritus, ICDD, USA

J. Dann, Consulting Editor, ICDD, USA

11:35-11:47 S-25 Energy Dispersive X-ray Diffraction to Answer the Question: “What's in the Box?"

S. Dorkings, Defence Science \& Technology Laboratory - UK Ministry of Defence, UK

11:48-12:00 S-41 Scanning Laue X-ray Nanodiffraction for Microstructural Imaging and Its Applications for Material Science

C.S. Ku, S.J. Chiu, C.Y. Chiang, National Synchrotron Radiation Research Center, Taiwan 
Chair: P. Pianetta, Stanford University, USA, pianetta@slac.stanford.edu

Co-chair: Y. Liu, SLAC National Accelerator Laboratory, USA, liuyijin@SLAC.Stanford.edu
8:30 S-26 Invited: Dreaming in Cool Colors: X-ray Microscopy to See What's There, and to Know What it is
C. Jacobsen, APS - Argonne National Laboratory, and Northwestern University, USA
9:00 S-13 Realtime X-ray Fluorescence Movie of Calcium and Iron in Growing Chemical Garden
W. Zhao*, University of Tsukuba, Japan
K. Sakurai, National Institute for Materials Science, Japan
$\begin{aligned} \text { 9:20 S-50 } & \text { X-ray Fluorescence Tomography Developments for Studies of Challenging Samples } \\ & \text { O. Antipova*, K. Kemner, S. Vogt, L.X. Li, D. Gursoy, Argonne National Laboratory, USA }\end{aligned}$
9:40 S-30 Novel Microstructured X-ray Source Designed for Grating-Based Phase Contrast Imaging
W. Yun*, S. Lewis, D. Reynolds, B. Stripe, A. Lyon, S. Chen, S. Seshadri, V. Semenov, J. Kirz, Sigray, USA
10:00 Break

10:30 S-54 Invited: Understanding Heterogeneities in Battery Materials through Multi-Modal X-ray Microscopy W.E. Gent*, Y. Li, J. Lim, W.C. Chueh, Stanford University, USA

11:00 S-24 Zinc $(\mathrm{Zn})$ and Lead $(\mathrm{Pb})$ Accumulation in the Tidemark of Articular Cartilage with High-resolution micro-XRF M. Rauwolf*, A. Turyanskaya, P. Wobrauschek, C. Streli, Atominstitut - TU Wien, Austria

A. Roschger, Max Planck Institute of Colloids and Interfaces, Germany

I. Pape, K. Sawhney, Diamond Light Source Ltd, UK

P. Roschger, Hanusch Hospital, Austria

J.G. Hofstaetter, Orthopaedic Hospital Vienna-Speising, Austria

11:20 S-39 Analyzing Challenging Materials with Micro-X-ray Fluorescence

C. Worley, Los Alamos National Laboratory, USA

11:40 S-20 Multimodal Imaging of Biological Samples: Correlation of $\mu$ XXF with MALDI-MSI and with LA-ICP-MS

A. Turyanskaya*, M. Rauwolf, L. Perneczky, P. Wobrauschek, C. Streli, Atominstitut - TU Wien, Austria

A. Svirkova, M. Bonta, A. Limbeck, M. Marchetti-Deschmann, CTA - TU Wien, Austria

A. Roschger, P. Roschger, Hanusch Hospital, Austria

Mineral Exploration and Mining

Amphitheatre

Chair: D.L. Bish, Indiana University Bloomington, USA, bish@indiana.edu

8:30 S-5 Invited: Handheld XRD Methods for Mining and Related Applications

G. Hansford, University of Leicester, UK

9:00 S-10 Invited: Practical Applications of Portable XRF in Mineral Exploration: Confessions of a Geochemist D. Arne, CSA Global, Canada

9:30 S-3 Detecting the Undetectable: Lithium by Portable XRF

N. Brand, Portable XRF Services and University of Western Australia, Australia

C. Brand, Portable XRF Services, Australia

9:50 F-17 Particle Size Effects in X-ray Fluorescence Analysis of Iron and Copper Minerals

B. Ganly*, J. Tickner, CSIRO, Australia

10:10 Break

10:40 S-21 Invited: First Impressions Count: Applications of Field Portable X-ray Diffraction to Environmental Monitoring of Mine Sites

C.C. Turvey*, S.A. Wilson, J.L. Hamilton, Monash University, Australia

S.M. Jowitt, University of Nevada Las Vegas, USA

G. Southam, The University of Queensland, Australia

11:10 F-46 Mg-carbonate Cements Trap Potentially Toxic Trace Metals and $\mathrm{CO}_{2}$ at Woodsreef Mine, New South Wales

J.L. Hamilton*, S.A. Wilson, B. Morgan, C.C. Turvey, Monash University, Australia

D.J. Paterson, Australian Synchrotron, Australia

J. McCutcheon, G. Southam, The University of Queensland, Australia 
11:30 F-78 Geochemical, Mineralogical, and Lithological Linkages in a Thick, Early Permian, Siliciclastic Succession, Midland Basin, West Texas, USA

A. Musgrove*, A. Morrell, P. Mainali, H. Rowe, N. Ganser, Premier Oilfield Laboratories, USA

11:50 S-33 Mineral Identification by Elemental Composition: A New Tool with PDF-4 Databases

T.G. Fawcett*, J.R. Blanton, S.N. Kabekkodu, T.N. Blanton, International Centre for Diffraction Data, USA

Polymers

Cheyenne Room

Chairs: B. Landes, Dow Chemical Company, USA, bglandes@dow.com

N.S. Murthy, Rutgers University, USA, murthy@biology.rutgers.edu

8:30 D-11 Invited: Novel Block Copolymer Morphologies Studied by GISAXS

K. Yager, Brookhaven National Laboratory, USA

9:00 D-29 Invited: SAXS Characterization of Nanocomposites and Polymer Matrix Composites

H. Koerner, Air Force Research Laboratory, USA

9:30 D-34 ICDD Full Diffraction Pattern Polymer Project - Applications in Pharmaceutical and Biomedical Materials

T. Blanton*, S. Gates-Rector, T. Fawcett, International Centre for Diffraction Data, USA

S. Misture, Alfred University, USA

9:50 D-40 Investigating Structures with Preferred Orientation Using X-ray and Neutron Scattering Techniques

Y. Mao, National Institute of Standards and Technology/University of Maryland, USA

10:10 Break

10:40 D-82 Invited: X-ray Scattering at the Advanced Light Source

A. Hexemer, Lawrence Berkeley National Lab, USA

11:10 D-75 Morphological Changes in HMPE Fibers Induced from Transverse Pressures and its Application to the Study and Mapping of Ballistic Impacts on Unidirectional Laminates

S.T. Correale, Honeywell International, Inc., USA

11:30 D-43 An X-ray Pole Figure Analysis on BOPE Films with Sequential Biaxial Drawing

Y. Tang, J. Yin, L. Liu, SINOPEC, Beijing Research Institute of Chemical Industry, China

B.B. He, Bruker AXS, Inc., USA

11:50 D-53 Surface X-ray Scattering Study of Segregation of PEG in Polymers

W. Wang, W.R. Lindemann, D. Vaknin, lowa State University, USA

N.S. Murthy*, Rutgers University, USA

General XRF and Environmental XRF

Lamar/Gibbon

Chairs: J. Kawai, Kyoto University, Japan, kawai.jun.3x@kyoto-u.ac.jp

R. Van Grieken, University of Antwerp, Belgium, rene.vangrieken@uantwerpen.be

8:30 F-11 Invited: Relation Between XANES Pre-edge and XRF K $\beta_{5}$ as the Changes of Chemical State, Local

Symmetry, and Coordination Number

T. Yamamoto, Tokushima University, Japan

9:00 F-32 Invited: XRF Related Activities at the IAEA Nuclear Science and Instrumentation Laboratory

A. Migliori*, R. Padilla-Alvarez, I. Darby, International Atomic Energy Agency (IAEA) Laboratories, Austria J. Osan, IAEA Laboratories, Austria and Hungarian Academy of Sciences, Hungary

9:30 F-34 Extracting Further Information from an X-ray Fluorescence Spectrum through Modeling of X-ray Scattering L.P. O'Neil*, D.C. Catling, W.T. Elam, University of Washington, USA

9:50 F-42 Leveraging XRF to Simplify Metals Analysis in Pharmaceuticals

S. Wood*, N. Lewen, M. Soumeillant, J. Qiu, J. Selekman, K. Zhu, Bristol-Myers Squibb, USA

10:10 F-55 3D-Polarized XRF Spectrometer with a 50kV and 4W X-ray Tube

T. Sugino, R. Tanaka, J. Kawai, Kyoto University, Kyoto, Japan

N. Shimura, RES Labo, Japan

$10: 30$

Break 
P. Prati, University of Genoa, Italy

11:30 F-1 The Advantages and Limitations of Handheld X-ray Fluorescence for Environmental Soil Screening M. Kreiner, Oxford Instruments, USA

11:50 F-40 Mercury Telluride XRF Calibration Standards

S.K. Zeisler*, V. Jaggi, I. Kaur, H.K. Oberoi, Micromatter Technologies Inc., Canada

12:10 F-71 Wasted Streams: The Downstream Legacy of Mine Waste from Derelict Mines

D.B. Gore*, K.A. Fryirs, T.J. Ralph, Macquarie University, Australia 


\section{Oral Sessions, Thursday Afternoon, 3 August}

*Signifies presenting author, when noted

Imaging II

South Mammoth

Chair: P. Pianetta, Stanford University, USA, pianetta@slac.stanford.edu

Co-chair: Y. Liu, SLAC National Accelerator Laboratory, USA, liuyijin@slac.stanford.edu

1:30 S-29 Invited: In-situ and Multi-modal X-ray Microscopy in Heterogeneous Catalysis

F. Meirer, Utrecht University, The Netherlands

2:00 S-14 X-ray Fluorescence Imaging of Buried Interface

W. Zhao, University of Tsukuba, Japan

K. Sakurai, National Institute for Materials Science, Japan

2:20 S-37 Sparse Macro-XRF Imaging of Large Works of Art

G. Pastorelli*, E. Pouyet, Q. Dai, O. Cossairt, A. Katsaggelos, M. Walton, Northwestern University, USA

2:40 S-27 Wavelength-Dispersive XRF Imaging Using Soller Slits and 2D Detector

K. Tsuji*, S. Aida, M. Yamanasghi, Osaka City University, Japan

T. Sakumura, K. Matsushita, T. Shoji, N. Kawahara, Rigaku, Japan

3:00

Break

$3: 30$

S-40 Multi-Model X-ray Microtomography for In-Situ Structure Quantification and Analysis

T. Xiao*, H. Xie, B. Deng, G. Du, R. Chen, G. Zhou, Y. Ren, Y. Wang, H. Tan, Y. Yang, L. Xu, T. Hu, Shanghai Institute of Applied Physics, China

3:50 S-42 Bragg Diffraction Transmission Microscopy Using Highly Monochromatic X-rays

S. Stoupin*, A. Campello, CHESS - Cornell University, USA

T. Kolodziej, A. Said, Y. Shvyd'ko, APS - Argonne National Laboratory, USA

4:10 S-17 The Lyncean Compact Light Source: A Miniature Synchrotron for your Laboratory

M. Feser*, R. Ruth, R. Loewen, Lyncean Technologies, USA

\section{Applied Materials I}

North Mammoth

Chairs: T.N. Blanton, International Centre for Diffraction Data, USA, tblanton@icdd.com

T. Fawcett, Emeritus, International Centre for Diffraction Data, USA, dxcfawcett@outlook.com

1:30 D-5 Invited: Crystal Structure Determination of Corrosion Products on Heritage Objects

S. Bette, R.E. Dinnebier*, Max-Planck-Institute for Solid State Research, Germany

G. Eggert, A. Fischer, Academy of Art and Design, Germany

2:00 D-69 Molecular Machinery Inside Crystalline Materials

V.N. Vukotic, University of Windsor and PROTO Manufacturing, Canada

2:20 D-76 Flash Sintering of Hydroxyapatite and Titania Composite Structures for Biomedical Applications

A. Choksi, T. Tsakalakos, H. Biçer, Rutgers University, USA

J. Okasinski, APS - Argonne National Laboratory, USA

2:40 D-62 Understanding the Mechanism of Flash Sintering with in situ EDXRD Experiments

S.K. Jha, T. Tsakalakos, Rutgers University, USA

3:00 Break

3:30 D-37 Qualitative and Quantitative Monitoring of Early Age Hydration of Volcanic Ash Blended Cement Using XRF and XRD

A. Joseph*, S. Al-Bahar, J. Chakkamalayath, Kuwait Institute for Scientific Research, Kuwait

3:50 D-10 Methodology and Determination of Water in Important Hydration Phases of Cements Afm (LDH)-Sulfate, Carbonate, Hydroxide Phases

H. Poellmann, University of Halle, Germany

4:10 D-3 Influence of Amino Acids on the Crystallization of Calcium Silicates Hydrates

S. Witzleben, A. Leiendecker, M. Wenzel, Bonn-Rhein-Sieg University, Germany 
Chair: C. Murray, IBM T.J. Watson Research Center, USA, conal@us.ibm.com

1:30

1:50

D-48

2:10

D-80

2:30

2:50

D-89

3:10

3:40

4:00

D-79

4:20

D-27

4:40

5:00

D-41 X-ray Crystallography with the EIGER R 4M Large-area HPC Detector

High Throughput Combinatorial Studies of Thermoelectric Materials

W. Wong-Ng*, J. Martin, M. Otani, S. Barron, N. Nguyen, E.L. Thomas, K.R. Talley, NIST, USA

Y. Yan, Wuhan University of Technology, China
C.I. Szabo*, E.G. Kessler, J.P. Cline, A. Henins, L.T. Hudson, M.H. Mendenhall, M.D. Vaudin, NIST, USA

Electrical Properties and Crystallization Study of Indium Oxide Thin Films Via Grazing-Incidence Wide-

Angle X-ray Scattering

G.B. Gonzalez*, J. Boesso, DePaul University, USA

J.S. Okasinski, J.D. Almer, Argonne National Laboratory, USA

D.B. Buchholz, L. Zeng, M.J. Bedzyk, R.P.H. Chang, Northwestern University, USA

D-78 Characterization of XANES Spectra for Olivine Group Minerals as a Function of Orientation and Composition

N. Valdez, M. Gunter, University of Idaho, USA

M.D. Dyar, Mount Holyoke College, USA

Advancing Clinical Diagnosis of Bone Diseases using X-ray Diffraction

C. Greenwood*, K. Rogers, Cranfield University, UK

R. Scott, Gloucestershire Royal Hospital, UK

M. Wilson, Science and Technology Facilities Council, UK

Break

-63 A Polycapillary Based Method of Monochromatic Time-Resolved X-ray Reflectivity

H. Joress*, J.D. Brock, A.R. Woll, CHESS - Cornell University, USA

Energy Dispersive Diffraction Imaging Using a New Germanium Strip Detector

J.S. Okasinski*, J.D. Almer, J. Baldwin, R. Woods, A. Miceli, O. Quaranta, APS - Argonne National

Laboratory, USA

S.R. Stock, Northwestern University, USA

D.P. Siddons, NSLS-II - Brookhaven National Laboratory, USA

Synchrotron tts Microdiffraction: from Data Acquisition to Structure Solution

J. Rius*, CSIC-Institut de Ciència de Materials de Barcelona, Spain

O. Vallcorba, ALBA Synchrotron Light Source, Spain

M. Mueller*, A. Förster, C. Schulze-Briese, DECTRIS Ltd., Switzerland

T. Ida, D. Hattan, Nagoya Institute of Technology, Japan

K. Nomura, Advanced Industrial Science and Technology, Japan

Trace Analysis including TXRF

Lamar/Gibbon

Chair: A. Pejovic-Milic, Ryerson University, Canada, anamilic@ryerson.ca

1:30 F-14 Invited: How to Establish a New Technique as a Standard: The Case of Total Reflection X-ray Fluorescence

L. Borgese*, L. Depero, University of Brescia, Italy

2:00

F-19

2:30

F-24

2:50

F-25

$3: 10$

F-26
Invited: X-ray Fluorescence Measurement of Bone Pb In Vivo: A Review and Prospects for Improvement

D. Chettle, McMaster University, Canada

Detection of Localized Tungsten Deposition and Speciation in Bone using $\mu$ XRF and $\mu$ XANES

C.R. VanderSchee*, D. Kuter, D.S. Bohle, McGill University, Canada

A Movement Towards the use of Portable X-ray Analyzers for the in vivo Measurements of Lead and Strontium in Bone

E. Da Silva, A. Pejovic-Milic, Ryerson University, Canada 
F-6 Confocal X-ray Fluorescence Microscopy Study on Plant Roots using Synchrotron Source

Z. Finfrock, Canadian Light Source Inc., Canada

S. Macfie, Western University, Canada

4:20 F-48 Perspectives and Opportunities in Plant and Food Science Research of Synchrotron Microscopy and Spectroscopy Techniques

D. Eichert, Elettra - Sincrotrone Trieste, Italy

4:40 F-41 Determination of Heavy Metals in Fruit Juices and Juice Blends by Total Reflection X-ray Fluorescence M. Schmeling*, J. Arroyo, K. Niaz, P. Sreerama, G. Sukhera, Loyola University Chicago, USA

5:00 F-59 Trace Element Analysis of Airborne Particulate Matter with TXRF and SR-TXRF-XANES J. Prost*, A. ZinkI, D. Ingerle, J.H. Sterba, P. Wobrauschek, C. Streli, Atominstitut - TU Wien, Austria D.M. Eichert, W.H. Jark, Elettra - Sincrotrone Trieste, Italy

G. Pepponi, Fondazione Bruno Kessler, Italy

A. Migliori, A.G. Karydas, M. Czyzycki, International Atomic Energy Agency, Austria A. Guilherme Buzanich, U. Reinholz, H. Riesemeier, M. Radtke, Federal Institute for Materials Research and Testing, Germany

5:20 F-73 Mercury Emissions Monitoring by TXRF

M. Garcia, N. Kumar, nanoRANCH-UHV Technologies, Inc., USA 


\section{Oral Sessions, Friday Morning, 4 August}

*Signifies presenting author, when noted

Energy Storage Materials

Lamar/Gibbon

Chair: M.A. Rodriguez, Sandia National Laboratory, USA, marodri@sandia.gov

8:30 S-49 Invited: In-situ and Ex-situ Characterization of Lithium Ion Batteries using X-ray and Neutron Diffraction Methods
A. Payzant, Oak Ridge National Laboratory, USA

9:00

S-44 Short-range Distortions and Long-range Cubic Order in Barium Titanate Nanoparticles

T. Monson, Sandia National Labs, USA

R. Haskell, S.H. Bang, Harvey Mudd College, USA

C. Shi, S. Billinge, Columbia University, USA

9:20 S-19 Crystal Structure in Bringing Excellent Electrochemical Properties in Alluaudite Type Sodium Insertion Materials

D. Dwibedi*, P. Barpanda, Indian Institute of Science, India

9:40

Break

10:00 S-58 Invited: Characterization of Energy Storage Materials with Energy-Dispersive X-ray Diffraction: Challenges and Insights

W.A. Paxton, Ford Motor Company, USA

$10: 30$

S-36 Development of a Novel sub eV, High Throughput, High Spatial Resolution, Laboratory X-ray Absorption Spectrometer for XANES and EXAFS Measurements

S. Seshadri, W. Yun. B. Stripe, D. Reynolds, A. Lyon, S. Lewis, J. Kirz, Sigray, Inc., USA

Applied Materials II

North Mammoth

Chairs: T.N. Blanton, International Centre for Diffraction Data, USA, tblanton@icdd.com

T. Fawcett, Emeritus, International Centre for Diffraction Data, USA, dxcfawcett@outlook.com

$8: 30$

D-83

9:00

D-12

9:20

D-66

9:40

10:00 D-74

$10: 20$

D-45

$10: 40$
Invited: Characterization of Aluminum Alloys for Cylinder Heads

T.R. Watkins*, M. Frost, K. An, L.F. Allard, D. Shin, A. Sabau, A. Shyam, J.A. Haynes, Oak Ridge National Laboratory, USA

S. Roy, Oak Ridge National Laboratory, USA and Indian Institute of Technology, India

S. Mirmiran, Y. Liu, Fiat Chrysler Automobiles North America, LLC., USA

A.F. Rodriguez, A. Gonzalez, Nemak Monterrey, Mexico

In-situ XRD studies of Microstructural Changes in Steel

M. Witte, Salzgitter Mannesmann Forschung GmbH, Germany

I. Janssen, Georg-August University Göttingen, Germany

In-situ EDXRD Study of Flash Sintering of Tin Oxide

H. Charalambous, S. Jha, T. Tsakalakos, Rutgers University, USA

Break

Flash Sintering of Ultrahigh Melting Temperature Covalent Nonoxide Ceramics at Low Temperatures with Low DC Electric Fields "An in situ EDXRD Study with a 200 keV Synchrotron Probe"

T. Tsakalakos, Rutgers University, USA

Understanding Processing Induced Defects and Decomposition in $\mathrm{PuO}_{2}, \mathrm{PuF}_{4}$ and Uranium Alloys

L. Sweet*, M. McCoy, J. Corbey, A. Casella, S. Jana, V. Joshi, S. Sinkov, C. Delegard, J. Tingey, G. Lumetta,

D. Meier, C. Lavender, K. Pitts, Pacific Northwest National Laboratory, USA

D-60 Flash Sintering of Bismuth Ferrite in situ with EDXRD

M. Wassel*, S. Jha, T. Tsakalakos, Rutgers University, USA

E. Gil-Gonzalez, L.A. Pérez-Maqueda, Instituto de Ciencia de Materiales de Sevilla, Spain 
Chair: M.G. Tucker, Oak Ridge National Laboratory, USA, tuckermg@ornl.gov

8:30 D-23 Invited: New Developments in PDF Software: Automatic Processing and Complex Modelling

P. Chater*, D. Keeble, M. Wharmby, T. Spain, J. Filik, H. Wilhelm, Diamond Light Source, UK

9:00 D-55 X-ray PDF to Quantify Defects in Disordered 2-D $\mathrm{MnO}_{2}$ Nanosheet Assemblies

P. Metz, S. Misture, Alfred University, USA

9:20 D-54 X-ray Absorption Spectroscopy with Other Simulation Techniques to Work on Amorphous and Nano-systems

Y. Zhang*, Oak Ridge National Laboratory, USA and Queen Mary, University of London, UK

A. Karatutlu, O. Ersoy, A. Sapelkin, Queen Mary, University of London, UK

9:40 Break

10:00 D-28 Invited: Multi-technique Structural Refinements Using the RMC Method

I. Levin, National Institute of Standards \& Technology, USA

10:30 D-59 Local Structural Distortions in the Boron Sublattice of Mixed Alkaline Earth Hexaborides Evidenced through Reverse Monte Carlo Modeling of X-ray Pair Distribution Functions

R.J. Koch*, P.C. Metz, S.T. Misture, Alfred University, USA

J. Cahill, O. Jaime, O. Graeve, University of California, USA

V.R. Vasquez, University of Nevada, Reno, USA

10:50 D-24 Application of Pair Distribution Function Analysis on Laboratory Diffractometer in the Temperature Range $80-1400 \mathrm{~K}$

O. Narygina*, M. Sommariva, C.A. Reiss, M. Gateshki, M.J. Fransen, PANalytical B.V., The Netherlands J. Quinn, PANalytical, Inc., USA

A. Pein, Anton Paar $\mathrm{GmbH}$, Austria

Industrial Applications of XRF

South Mammoth

Chair: D. Broton, Construction Technology Labs, USA, dbroton@ctlgroup.com

8:30 F-8 Applications of EDXRF Throughout the Food Industry

M. Kreiner, Oxford Instruments, USA

8:50 F-74 Online Real Time Metal Analysis during Pharmaceutical Manufacturing

M. Garcia, N. Kumar, nanoRANCH-UHV Technologies, Inc, USA

9:10 F-39 Industrial and Forensic Application of micro-XRF: Glass Analysis

S. Mamedov, Horiba Scientific, USA

9:30 F-63 Quality Control of Nanolayered Materials by XRR and GIXRF

D. Eichert, W. Jark, Elettra - Sincrotrone Trieste, Italy

9:50 Break

10:10 F-10 Surface Finish Thickness Determination on Printed Circuit Boards Sub-structures using Conventional XRF

F. Bogani, Intel Corporation, USA

10:30 F-9 Microstructure Analysis of Cement-Based Materials using micro X-ray Fluorescence

A.B. Giorla, E. Tajuelo-Rodriguez, S. Curlin, Y. Le Pape, T.M. Rosseel, Oak Ridge National Laboratory, USA A. Abd-Ellsamd, University of Tennessee, USA

10:50

F-60 A Chemostratigraphy-driven Workflow for the Analysis/Interpretation of Unconventional Core

H. Rowe, A. Morrell, P. Mainali, S. Narasimhan, N. Ganser, Premier Oilfield Laboratories, USA

11:10 F-43 Applications of Low Power Monochromatic WDXRF for Sulfur and Chlorine Analysis in Petroleum Industry Overview and Recent Developments

Z.W. Chen, L. Johnson, XOS, USA 
2017 Denver X-ray Conference Program-at-a-Glance $\diamond$ Monday - Friday 31 July - 4 August Monday Morning Workshops 9:00 am - 12:00 Noon

\begin{tabular}{|c|c|c|c|c|}
\hline & \multicolumn{4}{|c|}{ Meeting Rooms } \\
\hline & North Mammoth & South Mammoth & Amphitheatre & $\begin{array}{l}\text { Lamar/Gibbon } \\
\text {-unless noted as Cheyenne }\end{array}$ \\
\hline $\begin{array}{r}\text { Special } \\
\text { Topic }\end{array}$ & $\begin{array}{l}\text { Getting Started at User Facilities } \\
\text { (Lapidus) }\end{array}$ & & & \\
\hline XRD & & & $\begin{array}{l}\text { Specimen Preparation of XRD } \\
\text { (Fawcett) }\end{array}$ & \\
\hline XRF & & Basic XRF (Drews) & & $\begin{array}{l}\text { Trace Analysis including TXRF } \\
\text { (Wobrauschek/Streli) }\end{array}$ \\
\hline \multicolumn{5}{|c|}{ Monday Afternoon Workshops 1:30 pm - 4:30 pm } \\
\hline XRD & Stress (Noyan/Murray) & & Polymers (Landes/Murthy) & \\
\hline XRF & & Energy Dispersive (Lemberge) & & Micro XRF (Witherspoon) \\
\hline \multicolumn{5}{|c|}{ Monday Evening XRD Poster Session \& Reception 5:00 - 7:00 pm. Huntley Dining Room (Watkins/Rodriguez) } \\
\hline \multicolumn{5}{|c|}{ Tuesday Morning Workshops 9:00 am - 12:00 Noon } \\
\hline XRD & & & $\begin{array}{l}\text { Rietveld Refinement using In } \\
\text { Situ Powder Diffraction Data I } \\
\text { (Yakovenko/Kaduk) }\end{array}$ & \\
\hline XRF & $\begin{array}{l}\text { Handheld XRF - The Silver } \\
\text { Bullet or Fool's Gold (Loubser) }\end{array}$ & $\begin{array}{l}\text { Challenges in XRF Analysis } \\
\text { (Kawai) }\end{array}$ & & Quantitative Analysis I (Elam) \\
\hline \multicolumn{5}{|c|}{ Tuesday Afternoon Workshops 1:30 pm - 4:30 pm } \\
\hline $\mathrm{XRD}$ & $\begin{array}{l}\text { Strain \& Phase Mapping of } \\
\text { Industrial Materials \& } \\
\text { Processing by Synchrotron } \\
\text { (Tsakalakos) }\end{array}$ & & $\begin{array}{l}\text { Rietveld Refinement using In } \\
\text { Situ Powder Diffraction Data II } \\
\text { (Yakovenko/Kaduk) }\end{array}$ & \\
\hline XRF & & $\begin{array}{l}\text { Sample Preparation of XRF } \\
\text { (Anzelmo) }\end{array}$ & & Quantitative Analysis II (Elam) \\
\hline \multicolumn{5}{|c|}{ Tuesday Evening XRF Poster Session \& Reception 5:00 - 7:00 pm. Huntley Dining Room (Judges to be announced) } \\
\hline \multicolumn{5}{|c|}{ Wednesday Morning Plenary Session 8:30 am - 11:45 Inspecting the Infrastructure - Safeguarding with X-rays (Murray/Broton) Talus Room } \\
\hline \multicolumn{5}{|c|}{ Wednesday Afternoon Sessions } \\
\hline $\begin{array}{r}\text { Special } \\
\text { Topic }\end{array}$ & $\begin{array}{l}\text { New Developments in XRD \& } \\
\text { XRF Instrumentation I } \\
\text { (Blanton/Fawcett) }\end{array}$ & & & \\
\hline XRD & & & $\begin{array}{l}\text { Stress and Infrastructure } \\
\text { (Watkins) }\end{array}$ & Rietveld (Huq) \\
\hline XRF & & $\begin{array}{l}\text { Quantitative Analysis of XRF } \\
\text { (Brehm) }\end{array}$ & & \\
\hline \multicolumn{5}{|c|}{ Wednesday Evening Vendor Sponsored Reception 5:30 - 7:00 pm. Exhibit Hall/Yellowstone Conference Center } \\
\hline \multicolumn{5}{|c|}{ Thursday Morning Sessions } \\
\hline $\begin{array}{r}\text { Special } \\
\text { Topic }\end{array}$ & $\begin{array}{l}\text { New Developments in XRD \& } \\
\text { XRF Instrumentation II } \\
\text { (Blanton/Fawcett) }\end{array}$ & Imaging I (Pianetta/Liu) & $\begin{array}{l}\text { Mineral Exploration and Mining } \\
\text { (Bish) }\end{array}$ & \\
\hline $\mathrm{XRD}$ & & & & $\begin{array}{l}\text { Polymers (Landes/Murthy) } \\
\text { Cheyenne Room }\end{array}$ \\
\hline XRF & & & & $\begin{array}{l}\text { General XRF and } \\
\text { Environmental XRF } \\
\text { (Kawai/Van Grieken) }\end{array}$ \\
\hline \multicolumn{5}{|c|}{ Thursday Afternoon Sessions } \\
\hline $\begin{array}{r}\text { Special } \\
\text { Topic } \\
\end{array}$ & & Imaging II (Pianetta/Liu) & & \\
\hline XRD & $\begin{array}{l}\text { Applied Materials I } \\
\text { (Fawcett/Blanton) }\end{array}$ & & General XRD (Murray) & \\
\hline XRF & & & & $\begin{array}{l}\text { Trace Analysis including TXRF } \\
\text { (Pejovic-Milic) }\end{array}$ \\
\hline \multicolumn{5}{|c|}{ Friday Morning Sessions } \\
\hline $\begin{array}{r}\text { Special } \\
\text { Topic }\end{array}$ & & & & $\begin{array}{l}\text { Energy Storage Materials } \\
\text { (Rodriguez) }\end{array}$ \\
\hline XRD & $\begin{array}{l}\text { Applied Materials II } \\
\text { (Fawcett/Blanton) }\end{array}$ & & $\begin{array}{l}\text { Pair Distribution Function } \\
\text { (Tucker) }\end{array}$ & \\
\hline XRF & & $\begin{array}{l}\text { Industrial Applications of XRF } \\
\text { (Broton) }\end{array}$ & & \\
\hline
\end{tabular}




\section{LET OUR TEAM OF EXPERTS HELP YOU TAKE YOUR SKILLS TO THE NEXT LEVEL!}

Fundamentals of X-ray Powder Diffraction / XRD I:

5 - 9 June 2017

For the novice with some XRD knowledge, or for the experienced with an interest in the theory behind $X R D$, this clinic offers a strong base for increased lab performance.

The clinic covers instrumentation, specimen preparation, data acquisition and qualitative phase analysis through live demonstrations. It incorporates hands-on computer demonstrations of the latest software, including data mining with the Powder Diffraction File ${ }^{\mathrm{TM}}$ (PDF). Use of the powder diffractometer is featured with focus on topics pertaining to optical arrangement, factors affecting instrumentation profile width, choice and function of divergence slit, calibration and alignment, detectors, and X-ray optics.

Advanced Methods in X-ray Powder Diffraction / XRD II: 12 - 16 June 2017

For the experienced XRD scientist, this session aims to enhance analysis skills through intense problem solving. The course emphasizes computer-based methods of data collection and interpretation, for both qualitative and quantitative phase analysis, including an introduction to the Rietveld Method.

The advanced clinic covers factors affecting crystal d-spacings, diffraction-line intensities, structuresensitive properties (atomic scattering and structure factors), polarization effects, and multiplicity. Additionally, the clinic inspects specimen-sensitive (orientation, particle size) and measurement-sensitive effects (use of peak heights and peak areas), and addresses scanning condition options.

\section{Rietveld Refinement \& Indexing Workshop 1 \& 2/ 25-29 September 2017 Basic Workshop (1) / 25-27 September 2017 *Advanced Workshop (2) / 27-29 September 2017}

Powder pattern indexing and Rietveld structural refinement techniques are complementary and are often used to completely describe the structure of a material. Successful indexing of a powder pattern is considered strong evidence for phase purity. Indexing is considered a prelude to determining the crystal structure, and permits phase identification by lattice matching techniques. This workshop introduces the theory and formalisms of various indexing methods and structural refinement techniques along with quantitative analysis. One unique aspect of this workshop is the extensive use of computer laboratory problem solving and exercises that teach method development in a hands-on environment.

Take the three-day basic workshop, the three-day advanced workshop or attend both for a full week of hands-on training.

\section{Practical X-ray Fluorescence:}

Spring 2018

From theory to hands-on exercises, this course offers techniques and skills to improve lab performance. Discover the latest in cutting-edge instruments such as TXRF, hand-held devices, energy dispersive and wavelength dispersive spectrometers through live demonstrations.

The XRF course covers the basics of X-ray spectra; instrumentation design; methods of qualitative and quantitative analysis; specimen preparation and applications for both wavelength and energy dispersive spectrometry. The course emphasizes quantitative methods, use of automated X-ray spectrometers, review of mathematical matrix correction procedures, and new developments in XRF.
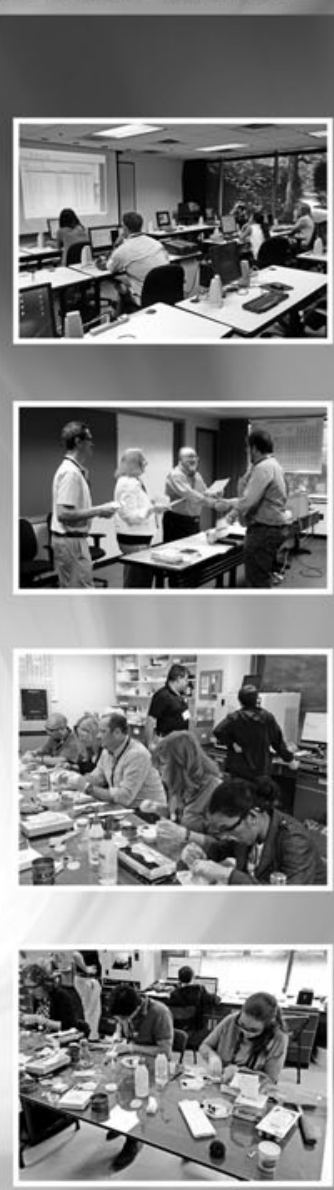

See the ICDD web site for prerequisites for the advanced Rietveld course.

\section{Register today at WWW.ICDD.COM/EDUCATION}

Please note: A minimum of 10 registrants per course is required, otherwise the course will be cancelled and your registration fee will be refunded. You will be notified of a course cancellation no later than two weeks prior to the start of the course.

\section{$\overline{g^{+}}$in $f \in$}

\section{LOCATION}

ICDD Headquarters, 12 Campus Boulevard Newtown Square, Pennsylvania 19073-3273 U.S.A
FOR MORE INFORMATION CONTACT

Eileen Jennings, Education Coordinator

Tel: 610.325.9814 Fax: 610.325.9823

Email: clinics@icdd.com 


\section{GRANT-IN-AID Program \\ JOIN ICDD'S ELITE GROUP OF SCIENTISTS \\ who contribute experimental powder diffraction patterns \\ to the Powder Diffraction File ${ }^{\mathrm{TM}}$.}

AS A MEMBER OF THIS ELITE GROUP, YOU WILL RECEIVE THE FOLLOWING BENEFITS:

- Financial support to aid current research

- Publication of pattern(s) in the Powder Diffraction File ${ }^{\mathrm{TM}}$ (PDF®)

- Receive calibration standards

- Purchase certain ICDD products at reduced prices

- Web-based access to the list of compounds in the ICDD master database includes published patterns, as well as patterns still in the editorial process

- First-time grantees receive a complimentary one-year subscription to Powder Diffraction

For over 50 years, ICDD has supported a well-developed program of grants to researchers around the world. One of our main objectives is to expand the range of reference materials by producing and cataloging high-quality diffraction patterns in our internationally renowned database, the Powder Diffraction File.Thanks to the longevity of this program, these contributions account for approximately a quarter of the current experimental file. ICDD awards financial support to qualified investigators in the form of grant-in-aid on a competitive proposal basis. The duration of a grant is 12 months with two cycles per year. Cycle I begins 1 April and Cycle II begins 1 October.

\section{THE FINER POINTS OF THE GRANT-IN-AID PROGRAM}

- Grant-in-Aid funds can be used most effectively as supplements to existing research projects involving the preparation and characterization of new materials, using powder diffraction techniques.

- Grant-in-Aid proposals will be considered, on a competitive basis, from any qualified investigator (academic, government, or industry), around the world, who can demonstrate expertise in the preparation of high quality powder diffraction patterns.

- Proposals addressing current opportunities to extend and improve the usefulness of the Powder Diffraction File ${ }^{\mathrm{TM}}$ are given highest priority.

- The duration of a Grant-in-Aid is 12 months. Renewal for additional 12-month periods may be considered on a competitive basis. Grant recipients are required to submit biannual progress reports.

- Deadlines for receipt of Grant-in-Aid proposals are due either by 31 July or by 31 January, depending on the cycle. Prior to submitting a grant proposal to the ICDD, please review the detailed Grant-in-Aid guidelines. These guidelines are available from ICDD's website at www.icdd.com/gia or by emailing the Grant Coordinator.

Any questions or comments regarding the ICDD Grant-in-Aid Program should be directed to:

\section{Celebrating 75 Years of} Serving the Scientific Community

Denise DelCasale, Grant Coordinator Email: delcasale@icdd.com

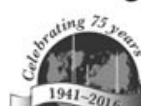

ICDD

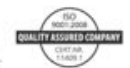

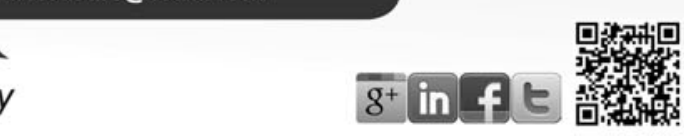

www.icdd.com | marketing@icdd.com

ICDD, the ICDD logo and PDF are registered in the U.S. Patent and Trademark Office Powder Diffraction File is a trademark of JCPDS - International Centre for Diffraction Data
Geographic Locations of Grants for the Past 15 Years:

Argentina

Austria

Brazil

Canada

Chile

Columbia

Czech Republic

France

Germany

India

Israel

Italy

Japan

Malaysia

Netherlands

P.R. of China

Poland

Portugal

Russia

Spain

Switzerland

Taiwan

Tunisia

Ukraine

United Kingdom

United States

Uruguay

Total Proposals Funded for the Past Fifteen Years: 682

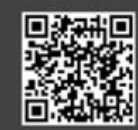

For more information on ICDD's Grant-in-Aid, visit www.icdd.com/grants 


\section{NTERNATIONAL CENTRE FOR DIFFRACTION DATA}

\section{隔 \\ I. II! \\ PDF-4/Organies 2017 \\ C \\ Solve Difficult Problems, Get Better Results}

\section{Comprehensive materials database featuring $516,000+$ organic and organometallic compounds}

- Features the largest collection of pharmaceuticals, excipients and polymers

- Highly targeted collection with special focus on materials used in commercial and regulatory fields

- Enhanced identification for crystalline, nano and amorphous materials
- Trade names for over 9,000 bioactive/ pharmaceutical entries

- Integrated data mining software

- Sleve+ search-indexing software (included as an added value)

\section{Combines powder diffraction and crystal structure reference data}

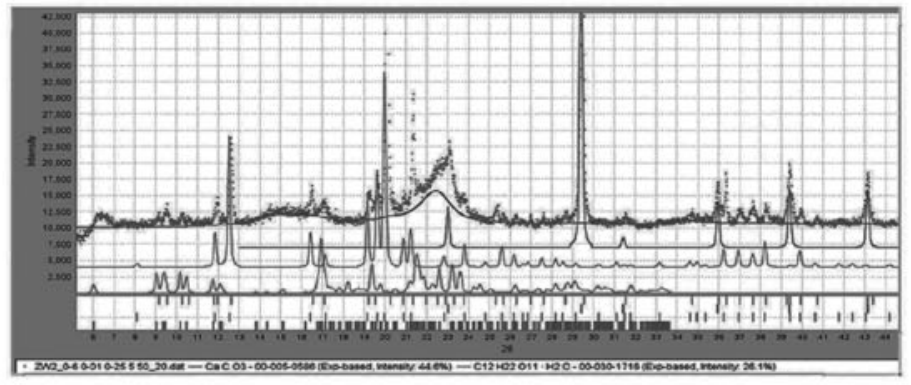

The four phase identification of the formulation of Lipitor uses references from a single crystal determination, an experimental powder pattern of cellulose $1 \beta$, a calculated powder pattern and pattern extracted from the patent literature. The identification required an inorganic excipient, polymer excipient and two organic compounds. A variety of reference materials and sources enabled the identification.

\section{COMPREHENSIVE・STANDARDIZED・QUALITY REVIEWED}

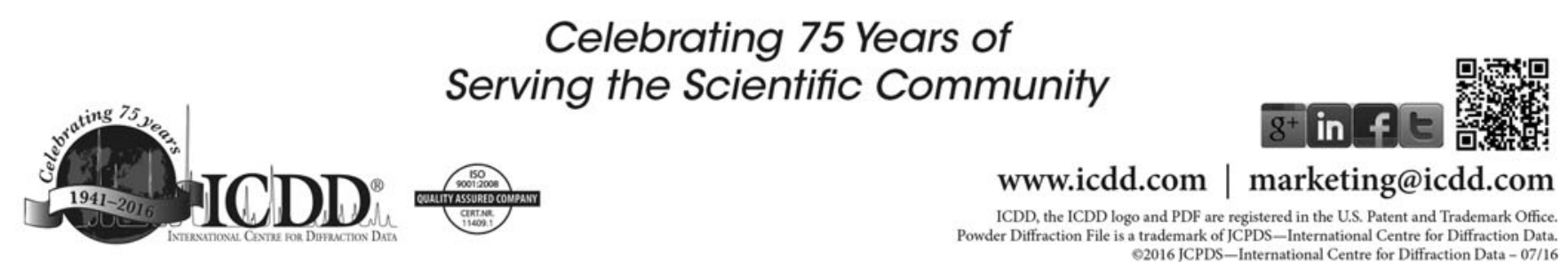




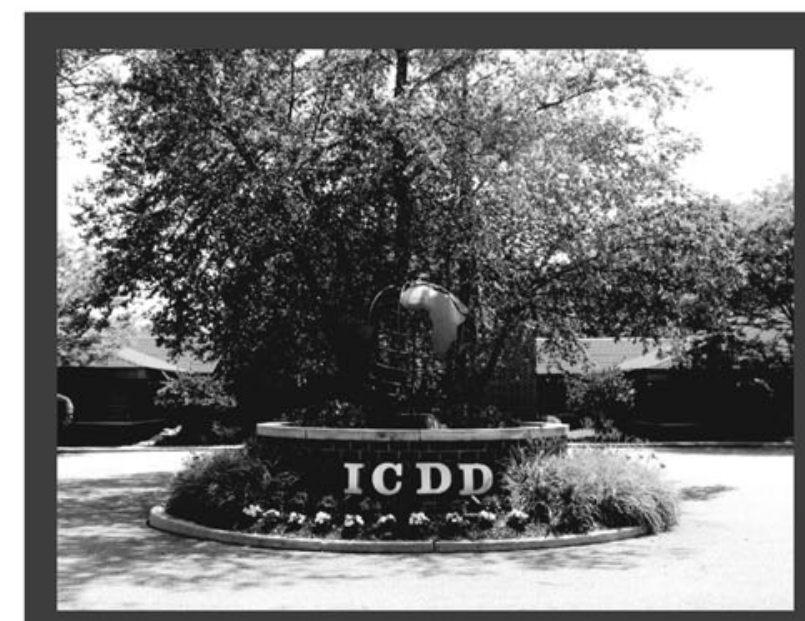

\section{ICDD's Vision}

The International Centre for Diffraction Data will continue to develop tools and support the education required for materials analyses of tomorrow.

\section{ICDD's Mission}

The International Centre for Diffraction Data will continue to be the world center for quality diffraction and related data to meet the needs of the technical community. ICDD promotes the application of materials characterization methods in science and technology by providing forums for the exchange of ideas and information.

\section{ICDD Products:}

- PDF-2

- PDF-4+

- WebPDF-4+

- PDF-4/Minerals

- PDF-4/Organics

- Sleve/Sleve+

\section{Education:}

- Clinics:

- XRD

- XRF

- Specialized Workshops

\section{Conferences:}

- Denver X-ray Conference (DXC)

- Pharmaceutical Powder X-ray Diffraction Symposium (PPXRD)

\section{Publications:}

- Powder Diffraction

- Advances in X-ray Analysis

\section{Grant-in-Aid Program}

ICDD databases are the only crystallographic databases in the world with quality marks and quality review processes that are ISO certified.

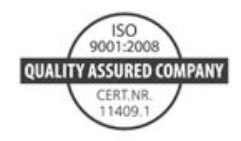

\section{Online Resources}

\section{Visit our website at www.icdd.com}

Our goal at ICDD is to help you solve your materials problems. We provide online publications, technical bulletins, tutorials, and videos. Many futorials focus on capabilities of the database, but there are also general tutorials that describe methods used to analyze drugs, polymers, and minerals. The tutorial page has links to free download publications, as well as instructional videos. Our website also contains over 1,000 full publications for free download from Advances in X-ray Analysis. Our website, tutorial page, and publication pages are there to help you!

www.icdd.com.resources/tutorials

www.icdd.com/products/technicalbulletins.htm

www.icdd.com/resources/axasearch/search_based_on_vol.asp

ICDD, the ICDD logo, PDF, and Denver X-ray Conference and design arr
registered in the US, Patent and Trademark OOfice. Powder Diffraction File is a trademark of the ICPDS-Intermational Centre for Diffraction Data
O2016 JCPDS-International Centre for Diffraction Data 
I N T E R N A T I O N A L C E N T R E F O R D I F F R A C T I O N

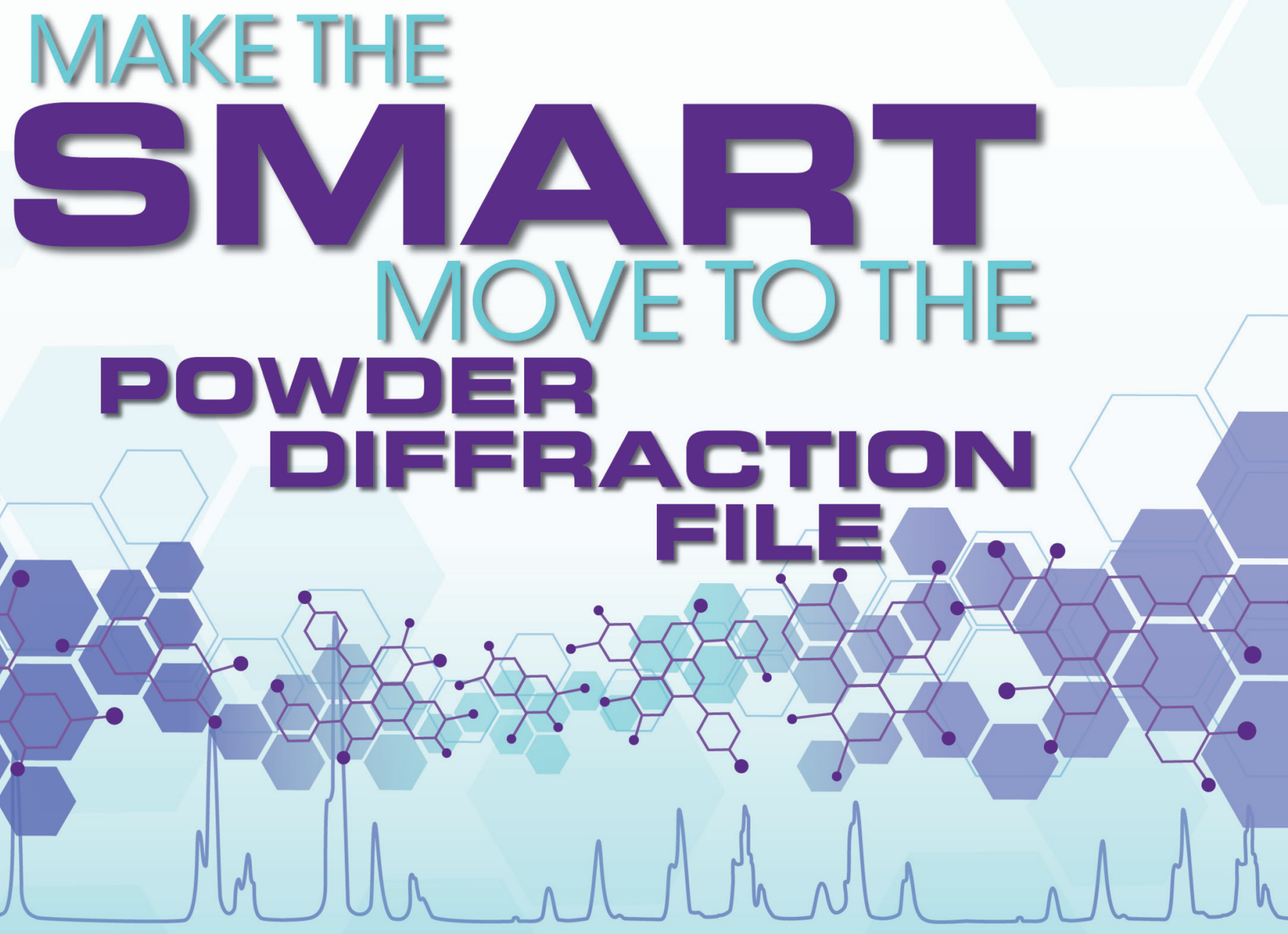

ICDD databases are the only crystallographic databases in the world with quality marks and quality review processes that are ISO certified.

Standardized data

More coverage

All data sets are evaluated for quality

Reviewed, edited and corrected prior to publication

Targeted for material identification and characterization

\section{Featuring over}

848,000

unique entries

\section{WWW.ICDD.COM}

Celebrating 75 Years of Serving the Scientific Community 


\section{improve your science}

with the AXRD Benchtop Powder Diffractometer

\section{FIND OUT WHY SO MANY SCIENTISTS ARE CHOOSING PROTO.}

www.protoxrd.com/powder

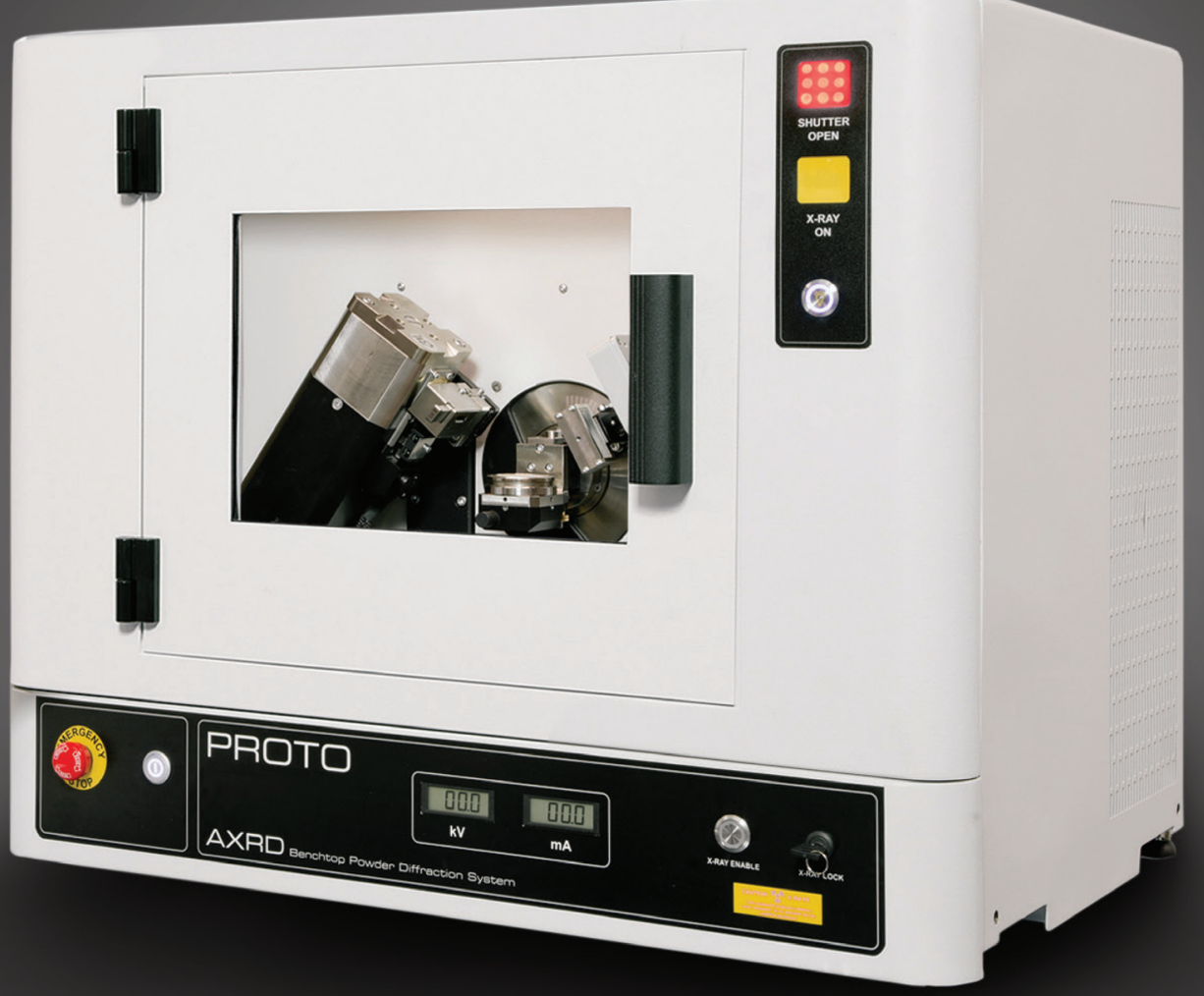

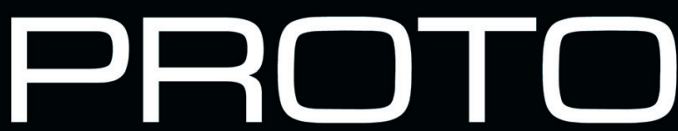

x-ray diffraction systems \& services
For more information and to download our product catalog.

1-734-946-0974 powder@protoxrd.com 